NBER WORKING PAPER SERIES

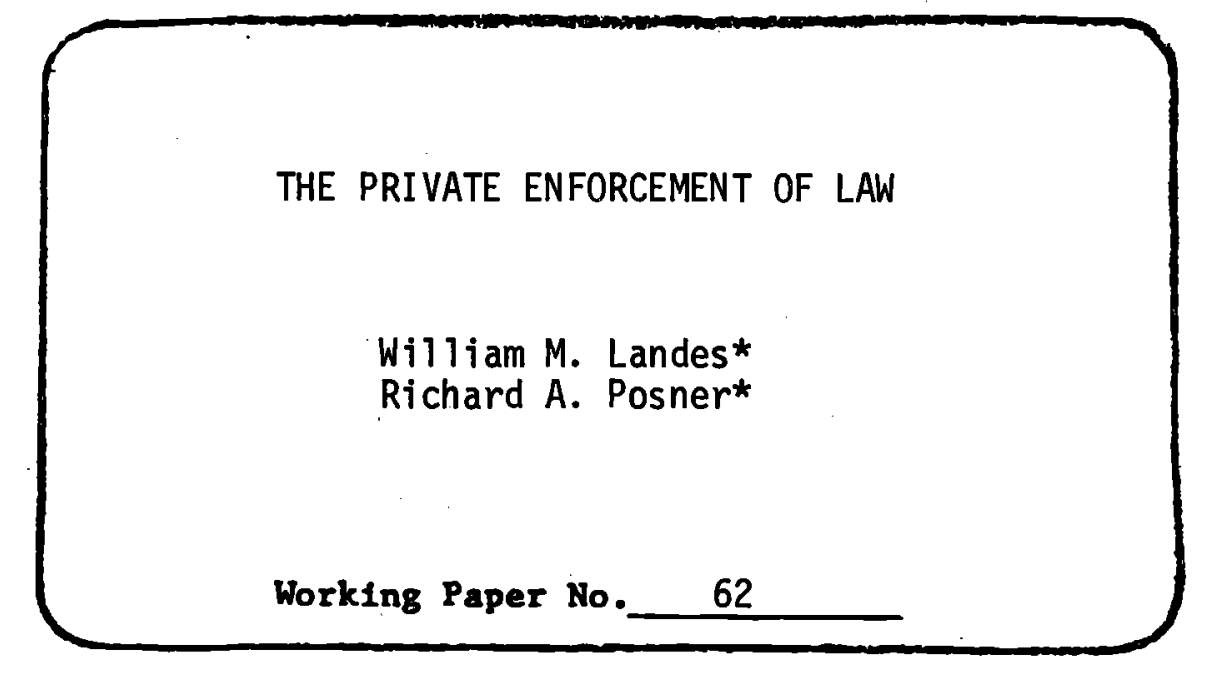

CENTER FOR ECONOMIC ANALYSIS OF HUMAN BEHAVIOR AND SOCIAL INSTITUTIONS National Bureau of Economic Research, Inc. 204 Junipero Serra Blvd., Stanford, CA 94305

\author{
November 1974
}

Preliminary; Not for Quotation

NBER working papers are distributed informally and In limited number for comments only. They should not be quoted without written permission.

This report has not undergone the review accorded official NBER publications; In particular. It has not yet been submitted for approval by the Board of Directors.

*The University of Chicago and NBER

Research on this paper was supported by a grant from the National Science Foundation to the NBER for its research in law and economics. 


\section{The Private Enforcement of Law}

William M. Landes* and Richard A. Posner**

Economists have begun to turn their attention to the process by which law is enforced, as well as the substance of legal rules. I/ An important question in the economic study of enforcement is the appropriate, and the actual, division of responsibilities between public and private enforcers. This question has been brought into sharp focus recently by an article in which Gary Becker and George Stigler advocate the privatization of law enforcement. 2/ Under their proposal, private individuals and firms would investigate violations, apprehend violators (including criminal offenders), and conduct legal proceedings to redress violations, including criminal prosecutions. A private enforcer would be entitled, if successful, to retain the entire proceeds of the suit--for example, the fine paid by the convicted offender. The unsuccessful enforcer would be required to reimburse the defendant's legal expenses.

Although Becker and Stigler's proposal may seem at first glance revolutionary and wholly unrealistic, on reflection it is evident that private enforcement is a pervasive feature of the existing social and economic system. In the enforcement of contract, tort, and property law, for example, the role of the state is limited essentially to furnishing a court system; indeed most contracts, both formal and informal, are "enforced" simply by the latent threat of withdrawing future business from the violator. 
Employers discourage employee corruption and malfeasance by dismissing an employee if his "violation" is detected. Until recently; bounties for dangerous or destructive animals were common, and the bounty systems had the essential features of the private enforcement system that Becker and Stigler propose. $3 /$ Many laws, notably the antitrust laws, are enforced by private as well as public entities; as we shall see, the contemporary antitrust class action has the essential features of the Becker-Stigler proposal. The use of paid informers by police departments, the Internal Revenue Service, and other public enforcement agencies is an example of private enforcement, here supplementary to public. Blackmail is another, if unconventional, example of the private enforcement of law-the blackmailer induces his victim, the violator of a legal or moral rule, to pay him a sum up to the amount that the violator would be willing to pay to avoid punishment. In effect punishment is imposed, but it is paid to the private enforcer who has discovered the violation. Bribery is very similar.

For many centuries, indeed, the enforcement of the criminal and regulatory laws of England (and doubtless of other countries as well) followed the pattern suggested by Becker and Stigler. Parliament and municipal authorities (as well as private firms and individuals) paid bounties for the apprehension and conviction of offenders, and in the case of offenses punished by fines, the fine was divided between the Crown and the enforcer. There were no public prosecutors, and the police were public in name only. 4 / This system of private enforcement was progressively abandoned during the nineteenth century, although traces of it persist to this day. Similarly in modern America private enforcement is much less 
extensive than Becker and Stigler contend would be efficient. This alleged discrepancy between the optimal and the actual is at least puzzling, in the light of recent findings that considerations of efficiency have played an important role in shaping the structure of the legal system and the behavior of its participants. $5 /$ The alternative possibility explored in the present article is that the area in which private enforcement is in fact clearly preferable to public enforcement on efficiency grounds is more restricted than Becker and Stigler believe; perhaps the existing division of enforcement between the public and private sectors approximates the optimal division.

Part I develops an economic model of competitive, profit-maximizing private enforcement. The model predicts the level of enforcement and the number of offenses that would occur in a world of exclusively private enforcement. 6/ Part II refines the model to account for the presence of monopoly in the private enforcement industry, different assignments of property rights in legal claims, the effect of taxing private enforcers, nonmonetary penalties, and legal errors--elements ignored in the initial development of the model in Part I. Part III contrasts our model with other economic approaches to the enforcement question. Part IV presents a number of positive implications of the model, relating to the choice between public and private enforcement of criminal versus civil laws, the assignment of exclusive rights to the victims of offenses, the budgets of public agencies, the discretionary nonenforcement of the law, and the legal treatment of blackmail and bribery. The positive implications of the model appear to be consistent with observations of the real world, although the findings in 
Part IV must be regarded as highly tentative. An appendix discusses the economics of rewards--an important method of compensating private enforcers.

\section{A MODEL OF ENFORCEMENT ACTIVITY}

A. The Equilibrium Conditions of the Private Enforcement Industry We define the output of the enforcement industry as the apprehension and conviction of offenders. Offenders include not only criminal offenders but also persons who commit torts, break contracts, violate the antitrust laws, etc. but for simplicity we limit the formal presentation to a single type of criminal offense where a unit of output requires both the apprehension and conviction of the offender. $7 /$ The output (A) is produced using two inputs: an aggregate of hired resources $(R)$ available at a constant per-unit price of $r$, and an input of criminal offenses (0). The enforcement production function is

$$
A=A(R, 0),
$$

where increases in both $R$ and 0 increase the industry's output (i.e., the marginal products of $R$ and 0 are assumed to be positive). $8 / A$ is "sold" to the state for a price equal to the fine paid by the convicted offender. (Later we consider situations in which the offender's penalty differs from the enforcer's return, for example where the offender is imprisoned and the enforcer receives a bounty from the state.) Since offenders are a source of potential income, the question arises as to the ownership of this asset. We assume initially the ownership scheme implied by the Becker-Stigler analysis: the first enforcer to apprehend and convict the offender is entitled to receive the fine. 9/ In Part II we shall modify this assumption and analyze the effects of enforcement on alternative property-right assignments, such as victim rights or state ownership.

To simplify the analysis still further, we assume an industry constant- 
returns-to-scale production function, so that (1) can be rewritten as

$$
A=0 p(R / 0),
$$

where $p=p(R / 0)$ is the probability of apprehension and conviction, which in turn is a positive function of the resources-to-offenses ratio $(R / 0)$. $10 /$ Alternatively, $\mathrm{p}$ is simply the ratio of apprehensions and convictions to the number of offenses.

The economic theory of deterrence predicts that the number of offenses will decline with an increase in the probability of apprehension and conviction and an increase in the penalty. 11/ That is,

$$
0=0(p, f) \text {, }
$$

where $\partial 0 / \partial p=0_{p}<0$ and $\partial 0 / \partial f=0_{f}<0$. Since we are assuming that only offenders are apprehended and convicted, $p$ in equations (2) and (3) is identical.

A competitive enforcement industry, consisting of a large number of firms that acquire property rights to offenses on a first-come first-served basis, will act as if the number of offenses were unaffected by enforcement activity. Yet expansions in the output of each firm will reduce--though by a negligible amount--the supply of offenses available to all other firms. The sum of these negligible external effects is not negligible and hence offenders will be deterred, and the supply of offenses will fall, as the industry attempts to expand its output. This in turn will lead the industry to readjust its level of enforcement activity. Moreover, as shown below, attempts by the industry to expand its output in response to changes in certain parameters may actually lead to a reduction in the industry's output after it fully adjusts to changes in the number of offenses. 12/ 
Since all firms are presumed to be equally efficient and (from the assumption of an aggregate constant-returns-to-scale production function) there are no entrepreneurial resources specialized to the industry, competition among firms will eliminate all profits and other rents. Total receipts in equilibrium will therefore equal total costs, as in

$$
f \cdot A=r \cdot R \text {, }
$$

which can be rewritten

$$
f=r /(0 / R) p .
$$

The denominator in (5) is simply the average product of the hired resource. 13/ Equilibrium, moreover, requires that values of $p$ and 0 that satisfy (5) be consistent with the values of $p$ and 0 implied by the offenders' supply function specified in (3).

The enforcement industry equilibrium together with the offender-supply equilibrium is illustrated in Figures 1 and 2. At a fine equal to $f_{0}$, both the equilibrium output, $A_{0}$ in Figure 1 , and the number of offenses, $0_{0}$ in Figure 2, are simultaneously determined. $A_{0}$ and $0_{0}$ must satisfy the conditions [Insert Figures 1 and 2] that the fine equal average cost for enforcers $\left(f_{0}=r /\left(0_{0} / R_{0}\right) p_{0}\right)$ and that the resulting probability $\left(p_{0}\right)$ yield a level of offenders equal to $0_{0}$ in Figure 2. The industry average cost curve $(A C)$ is drawn on the assumption that the supply of offenses is fixed at $0_{0}$. Average cost is rising, therefore, since an increase in $A$ (with 0 constant) comes about by increasing the industry's inputs of $R$, which lowers the average product of $R$ (as $R / 0$ rises) and raises average cost. 14/ Any movement along the average-cost curve in Figure 1, however, would alter the probability of apprehension, inducing a change in 0 via the offense function in Figure 2, and lead to a shift in the average-cost curve. Thus, there is only one possible 
$6 a$.

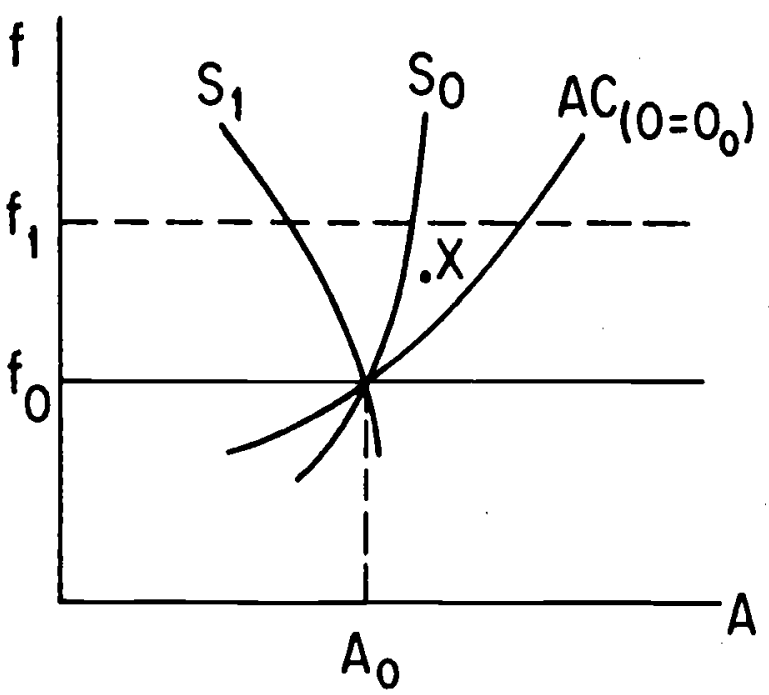

Figure I

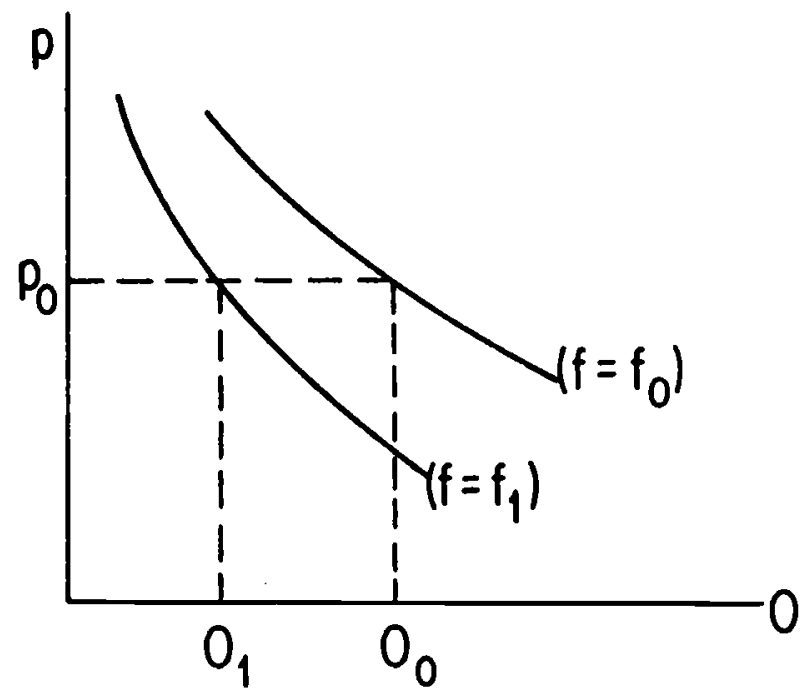

Figure II 
equilibrium point along a given average-cost curve.

The stability of the equilibrium in Figure 1 can be shown as follows. Suppose offenders adjust immediately to changes in $p$ and let $A$ exceed $A_{0}$ in Figure 1. Since $p$ is now greater than $p_{0}$, the number of offenses will fall below $0_{0}$ and the average-cost curve will shift upward, so that the industry will be operating at a point such as $X$ in Figure 1 . With average cost exceeding the fine, however, firms will leave the industry or reduce their output, reducing the ratio of $R$ to 0 and lowering both average cost and p. This in turn will increase the number of offenses, which will shift the average-cost curve downward. Adjustments by both firms and offenders will continue until industry output returns to $A_{0}$. Similarly, if $A$ were initially less than $A_{0}$ and hence the volume of offenses exceeded $0_{0}$ (as $p$ fell below $p_{0}$ ), increases in $R$ and decreases in 0 would return the industry to $\mathrm{A}_{0}$.

We now explore the implications of changes in several parameters of the model.

1. Change in the Crime Rate. Suppose there is an exogenous increase in the crime rate with $f$ constant. The offense function in Figure 2 will shift to the right. Let us assume that if $p$ remained fixed at $p_{0}$, the number of offenses would rise by 20 per cent. The number will initially by rise/more than 20 per cent because with $A$ unchanged, $p$ will fall below $p_{0}$. In response to the increase in offenses, average cost will fall below $f$ and the industry will attempt to expand output. Since $f$ is unchanged, the competitive equilibrium will be restored when the average product of $R$, and hence average cost, return to their original levels. This requires a proportional increase in $R$ equal to the 20 per cent increase in offenses 
in order to keep $\mathrm{R} / 0$ constant. In terms of Figure 1 , the average cost curve will have shifted to the right by 20 per cent and arrests and convictions will have risen by 20 per cent, while p will have remained constant. $15 /$

2. Change in the Costs of Conviction. Assume that the costs of convicting offenders rise as a result of a procedural change, for example requiring higher standards of proof or excluding most confessions. $16 /$ Initially, this would reduce $p$ in Figure 1 , lower the average product of $R$, and raise average cost. In response, firms would begin to cut back on their enforcement expenditures and the number of offenses would increase. At the new equilibrium (at the unchanged fine of $f_{0}$ ) the ratio of 0 to $R$ will have risen and $p$ will have fallen in comparison to their original values.

3. Change in the Fine. Suppose the legislature increases the fine for the particular offense from $f_{0}$ to $f_{1}$, as $i l l u s t r a t e d$ in Figures 1 and 2. If we assume that offenders adjust immediately to changes in $p$ and $f$, the number of offenses will fall below $0_{1}$. 17/ It is not obvious whether the enforcement industry at its original output of $A_{0}$ is now operating where average cost is less or greater than the new price. The decline in offenses may be of sufficient magnitude to raise average cost (and reduce the average product of $R$ ) proportionately more than the increase in $f$. In that event firms will exit from the industry or reduce their levels of output, and $R$ and $A$ will decline. Alternatively, if the reduction in offenses still leaves average cost below $f_{1}$, output will expand. In equilibrium--where profits are competed away--average cost must rise by the same proportion as $f$ rises. Since we have assumed that there are no scale effects in the enforcement industry (from the assumptions of constant returns to scale and a fixed price of $R$ ) average cost will rise (and the 
average product of $R$ will fall) only if the ratio of $R$ to 0 increases. of particular importance is the fact that the increase in the equilibrium ratio of $\mathrm{R}$ to 0 also produces an increase in $\mathrm{p} .18 /$ Thus, although there is no clear prediction as to the number of apprehensions and convictions when the fine increases (as indicated by the two possible supply curves, $S_{0}$ and $S_{1}$, in Figure 1$)$, the model unambiguously predicts an increase in the probability of apprehension and conviction.

The intuitive explanation of this relationship between $p$ and $f$ is as follows. An offenses by increasing the expected cost of an offense, and it increases the returns to enforcers from apprehending an offender. The latter effect may well, though it need not, lead to an increase in the number of apprehensions. If so, it is clear that the result will be an increase in the probability of apprehension and conviction. The less intuitive case is where the increase in the penalty has so great a deterrent effect on offenders that it results in a reduction in the scale of the enforcement industry, i.e., in fewer apprehensions. Still, the return per apprehension is higher, and therefore the industry will spend greater resources than before per apprehension. This in turn implies that the ratio of the industry's total expenditures to the number of offenders will be higher, since otherwise the average cost of catching an offender would not have risen. If more resources are being spent per offender, the probability of apprehenshion will rise.

The positive relationship, under private enforcement, between the probability of apprehension and conviction and the penalty has, as we show next, important implications for comparisons between private and optimal public enforcement. 
10.

B. Optima1 Public and Private Enforcement Compared

We follow Becker in defining the social loss from crime as

$$
L=D(0)+C(0, p)+b p f 0,
$$

where $D$ is the net damages (harm to victims minus gain to offenders), $c(0, p)$ is the costs of apprehension and conviction, and bpfo is the social costs of punishment. $19 /$ However, we make several simplifying assumptions :

(1) Al1 penalties are fines and the costs of collecting them are zero. Hence bpfo is zero.

(2) The aggregate enforcement production function yields constant returns to scale.

(3) The cost of apprehending and convicting offenders is identical under private and public enforcement--that is, technological conditions, enforcement incentives, and factor prices are independent of whether enforcement is public or private.

(4) Fines greater than $f^{\star}$ are uncollectable because they exceed the offender's resources, and hence they would have no greater deterrent effect than $f^{*}$. 20 I

(5) When $f=f^{*}$ and $p$ is arbitrarily close to zero, net marginal damages are both positive (i.e., $D^{\prime}>0$ ) and an increasing function of the number of offenses (i.e., $D^{\prime \prime}>0$ ). $\underline{21 /}$ If the social loss is then minimized with respect to $p$ and $f$, the fine will be set at the maximum amount collectable $\left(f^{\star}\right)$ and $L$ will be minimized with respect to $p$. 22/ As $p$ rises however, the decline in marginal damages due to the reduction in offenses must be balanced against the marginal costs (assumed to be positive) of increasing $p$. 
丹. [- The increasing costs of enforcement as the number of offenses falls is the source of our final assumption: $\mathscr{H}_{(6)}$ the optimal number of offenses derived from the social loss function is always positive. $23 /$

Assumptions (4), (5) and (6) merely formalize what one observes in the real world--a positive number of offenses, and an enforcement system that combines penalties with apprehensions and convictions. will be

Our first step $/$ to determine the appropriate fine under private enforcement. We shall then compare the number of apprehensions, offenses, etc. at this fine under public and private enforcement.

Minimizing the social loss function (6) with respect to $p$ and $f$ subject to the constraint of private enfor cement, that is, subject to

$$
f-r /(0 / R) p=0,
$$

yields the first-order equilibrium condition

$$
\frac{-\partial L / \partial f}{\partial L / \partial p}=\frac{p^{2} p^{\prime}}{r\left(p-p^{\prime}(R / 0)\right.}
$$

where $\partial L / \partial f$ and $\partial L / \partial p$ are the changes in the social loss resulting from infinitesimalincreases in $f$ and $p .24 /$ The left-hand side of (8) denotes the rate at which a change in $p$ is traded off for a unit change in $f$ to maintain a constant social loss, while the right-hand side denotes the rate at which enforcers change $p$ in response to a unit change in f. $\underline{25 /}$ Observe that $-(\partial L / \partial f) /(\partial L / \partial p)$ is positive when $(8)$ holds since the right-hand side of (8) is always positive.

To provide a more intuitive understanding of the equilibrium conditions and their implications for private versus public enforcement, we introduce the concept of social loss indifference curves (SLIC). A given SLIC shows various combinations of $p$ and $f$ that yield a constant social loss, and its slope is 


$$
\left.\frac{d p}{d f}\right|_{d L=0}=\frac{-\partial L / \partial f}{\partial L / \partial p}=\frac{D^{\prime} 0_{f}+r(R / 0) 0_{f}}{D^{\prime} 0_{p}+\frac{r}{p^{\prime}} 0\left(1-\tilde{p} \varepsilon_{p}\right)}
$$

where $\tilde{p}=p^{\prime} \cdot(R / 0) / p$, and $\varepsilon_{p}=-0, p(p / 0)$. 26/ The location and shape of SLIC's are determined as follows. At the maximum collectable fine ( $f^{*}$ in Figure 3), find the $p$ that (locally) minimizes the social loss function, and repeat for smaller and smaller fines. The curve labeled $\partial L / \partial p=0$ in Figure 3 is a locus of points showing the value of $p$ that minimizes the social loss for different values of $f$. This curve is (typically) negatively sloped, indicating that an exogenous increase in $f$ leads to a reduction in $p$ under a system of optimal public enforcement. $27 /$ This result is in sharp contrast to the positive impact of increases in $f$ on $p$ in a system of private enforcement, illustrated in Figure 3 by the positively sloped curve $P R_{1}$. When $f<f^{*}$, the slope of each SLIC (see equation (9)) at the point where it intersects the curve labeled $\partial L / \partial p=0$ is vertical (infinite since $\partial L / \partial p=0$ and $\partial L / \partial f<0 . \underline{28 /}$

\section{[Insert Figure 3]}

At points above $\partial L / \partial p=0$, the SLIC slope is positive because increases in $p$ raise the social loss and this must be compensated for by an increase in $f$ to maintain a constant social loss. Similarly, at points below $\partial L / \partial p=0$ the SLIC slope is negative because increases in both $p$ and $f$ lower the social 1oss。

Several indifference curves $\left(I_{1}, I_{2}\right.$, and $\left.I_{3}\right)$ are $i l l u s t r a t e d$ in Figure 3. 29/ Since the social loss falls as $f$ increases with $p$ constant (from the assumption that $\left.D^{\prime}>0\right), I_{1}$ represents a lower social loss than $I_{2}$, etc. 
12a.

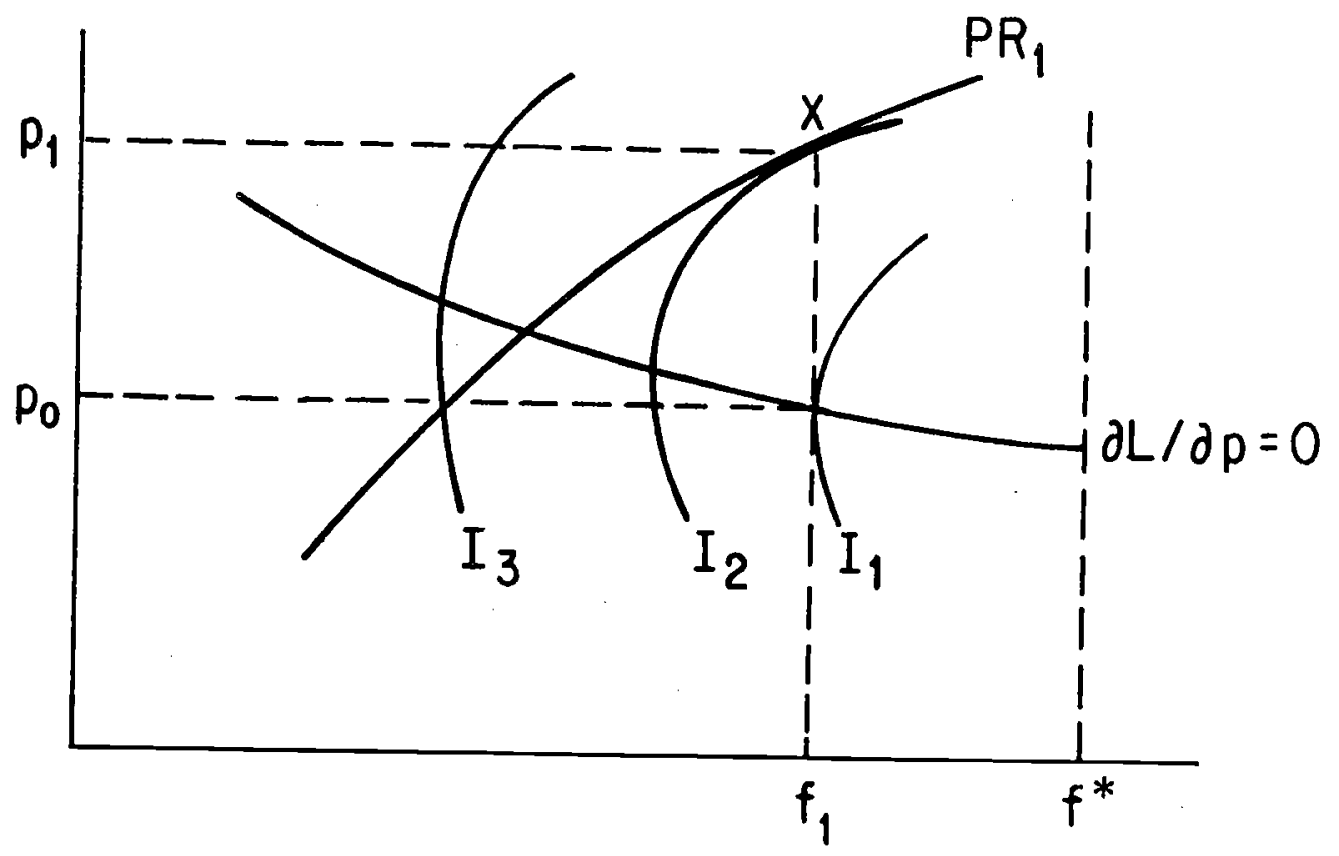

Figure III 
More generally, the further to the right the indifference curve in Figure 3 , the lower the social loss. The optimal $p$ and $f$ in Figure 3 are found by equating the rate at which profit-maximizing enforcers increase $p$ in response to a change in $f$ to the rate at which $p$ must increase as $f$ increases to maintain an unchanged social loss. $30 /$ This occurs at point $X$ in Figure 3 where the optimal fine and probability are $f_{1}$ and $p_{1}$ respectively. At this point, however, the indifference curve is positively sloped, which implies that a reduction in $p$ would lead to a lower social loss $(\partial L / \partial p>0)$. The minimum social loss at $f_{1}$ occurs along the curve labeled $\partial L / \partial p=0$ in Figure 3--and along this curve the value of $p\left(=p_{0}\right)$ is less than the corresponding $p\left(=p_{1}\right)$ generated by private enforcement. Put differently, the "best" one can do under private enforcement is to set a fine equal to $f_{1}, 31 /$ but at $f_{1}$ one observes a greater probability of apprehension and conviction $\left(p_{1}>p_{0}\right)$ and a greater social loss under private than optimal public enforcement. 321

The intuitive explanation for the overenforcement theorem is straightforward. If the probability of apprehension and conviction were unity, the optimum fine would be set equal to the social costs of illegal activity--i.e., to the value of crime prevention. If the value of crime prevention rose because the harm from crime was increasing, the optimum fine would rise by the same amount. This would be perceived by enforcers as an upward shift in the demand curve facing them, and would have the effect of increasing the resources devoted to crime prevention, as in the case of an ordinary product the demand for which increases. The difficulty arises because in the design of an optimum system of penalties where the probability of apprehension and conviction is less than unity, the fine is set higher 
than the social costs of the illegal activity not as a signal that additional resources should be devoted to the activity because its value has increased relative to other activities but rather as a device for attempting to minimize those resources. A fine so set communicates the wrong signal, from a social standpoint, to the private enforcer. In the case of public enforcement, the high fine need not be taken as a signal to invest greater resources in crime prevention, since the public enforcer is not constrained to act as a private profit maximizer. $33 /$

In showing that private enforcement is less efficient than optimum public enforcement, we have not established a case for preferring public to private enforcement. That would require a comparison between private and actual, not optimal, public enforcement, a comparison very difficult to make without a theory of the behavior of public enterprises. The excessenforcement theorem is nonetheless useful, as shown in Part IV, in explaining policies designed to limit the scale of law-enforcement activities.

\section{SOME EXTENSIONS OF THE MODEL}

The model of private enforcement developed in the previous part contains a number of restrictive assumptions, such as that enforcement is competitive, rights in legal claims are assigned on a first-come first-served basis, enforcers are not taxed, penalties always take the form of monetary fines, and errors in enforcement never occur. These assumptions will now be relaxed.

\section{A. Monopoly Enforcement}

If the private-enforcement industry is monopolistic rather than competitive, it will take account of the fact that increases in the level of enforcement reduce the number of offenses. The result will be fewer convictions and higher profits than under competition. $34 /$ 
The monopolist maximizes

$$
\Pi=f O p=r R
$$

with respect to $R$. This yields

$$
f=\frac{r}{p^{\top} \omega}
$$

where

$$
\omega=\left(1-\varepsilon_{p}\right) /\left(1-\tilde{p} \varepsilon_{p}\right),
$$

and $0<\tilde{p}, \varepsilon_{p}, \omega<1$. 35 In equation (11), r/p'w equals the marginal cost of apprehensions and convictions. Marginal cost is greater, the smaller p' and the larger $\varepsilon_{p}$ (since $\omega$ is inversely related to $\varepsilon_{p}$ ). As $\varepsilon_{p}$ approaches unity, marginal cost approaches infinity since additional expenditures on enforcement produce no additional apprehensions. Since p', the marginal product of $R$ in producing apprehensions and convictions (assuming 0 constant), is a decreasing function of $R / 0$, marginal cost will also be an increasing function of output (see Figure 4). $\underline{36 /}$

\section{[Insert Figure 4]}

Figure 4 shows that competition yields a level of enforcement greater than the level produced by a monopolist $\left(A_{0}>A_{0}{ }^{*}\right)$ even though demand is infinitely elastic. At $A_{0}$ marginal cost exceeds average cost, and a profit-maximizing monopolist would reduce enforcement until marginal cost equaled $f_{0^{\circ}} .37 /$ Monopoly will thus be associated with fewer apprehensions and convictions, a greater number of offenses, and a lower probability of apprehension and conviction than competition. $38 /$

The optimal fine and level of enforcement under monopoly are determined by minimizing the social loss function subject to the constraint specified in (11) that marginal revenue equal marginal cost. This yields the following first-order condition. $39 /$ 
15a.

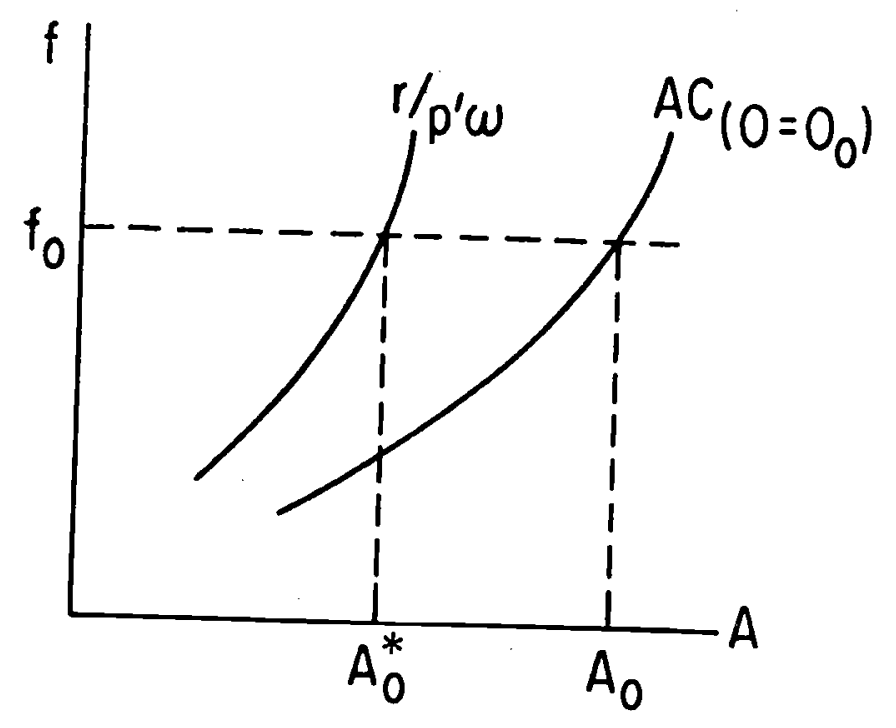

Figure IV 


$$
\frac{-\partial L / \partial f}{\partial L / \partial p}=\frac{-\omega\left(p^{\prime}\right)^{3}}{r p^{\prime \prime}}
$$

The left-hand side of (13) is the slope of the social loss indifference curve (SLIC) while the right-hand side (which is always positive) is the rate at which the monopolistic enforcer increases $p$ in response to a unit increase in $\mathrm{f}$. Figure 5 illustrates the determination of the optimal $p$ and $f$ under monopoly and competition. $P R_{2}$ is the constraint under which the monopolistic enforcer operates and $\mathrm{PR}_{1}$ the constraint of the competitive enforcement industry. Since the profit-maximizing $p$ at each $f$ is lower under monopoly than under competition, and the rate at which the monopolistic enforcer increases $p$ in order to maximize profits in response to an increase in $f$ is lower than the rate under competition, $40 /$ the monopolistic enforcer attains a higher social loss indifference curve (i.e., a lower social loss). We emphasize that excessive enforcement results even under monopoly, because the point of tangency between the PR curve and the social loss indifference curve still occurs in a region where the latter curve is positively sloped so

one can find a lower $p$ (holding $f$ constant) that yields a lower social loss.

\section{[Insert Figure 5]}

In sum, private competitive enforcement (with property rights obtainable only on a first-come first-served basis) yields a greater social loss from crime (considering all relevant costs) than private enforcement by a monopolist or cartel. Although the optimal fine is smaller under competitive than monopolistic enforcement, the equilibrium $p$ may be greater or smaller. In Figure $5, p_{1}$ is greater than $p_{2}$ but this need not be true 


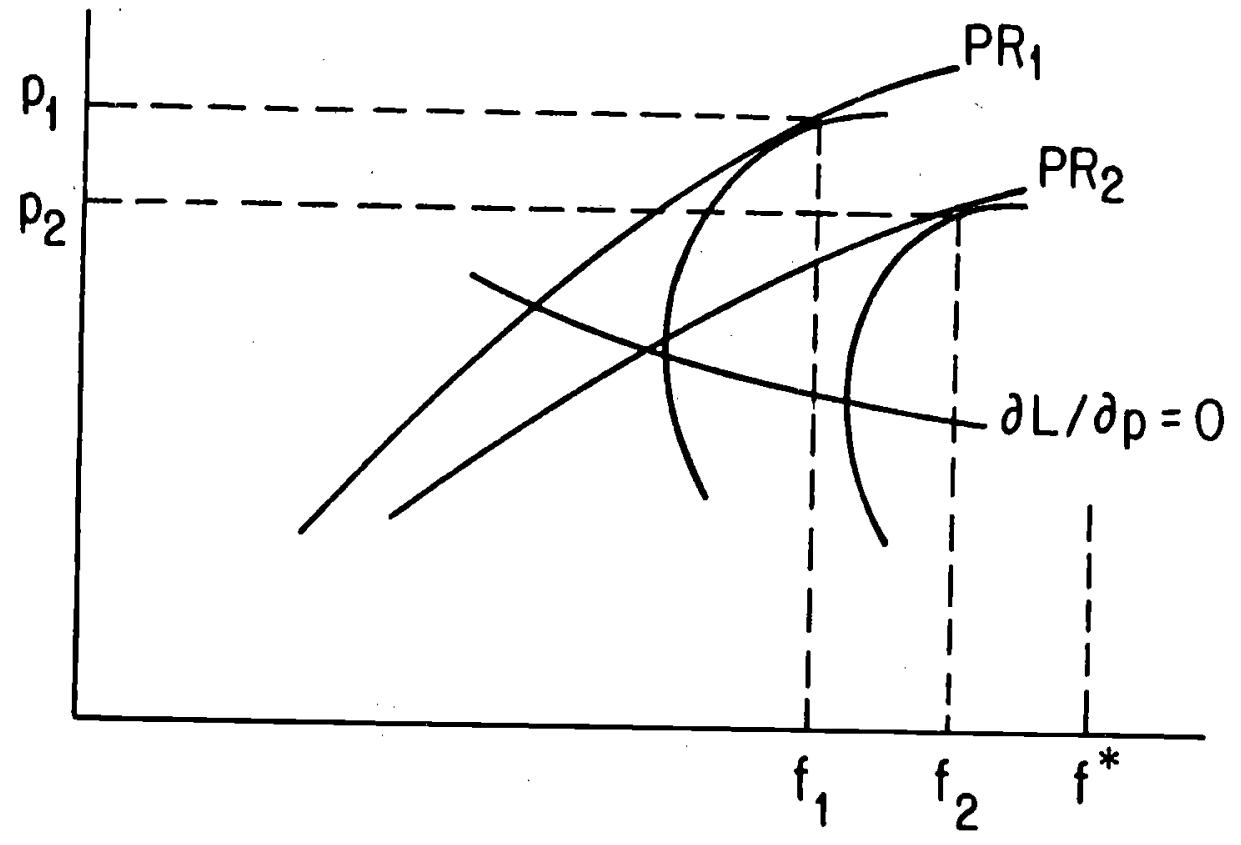

Figure V 
in general. This finding modifies our earlier result, where for a given $f$ the value of $p$ was always greater under competition than monopoly. When the fine is also endogenous, it will be higher under monopoly than under competition. This will induce an increase in $p$ and it will no longer be possible to predict that $\mathrm{p}$ will be smaller under monopoly.

B. State and Victim Ownership of Property Rights in Legal Claims

In the well known analysis of a free-access resource, competition carries the level of production "too far" because social marginal cost exceeds price at the competitive output. The problem is the absence of property rights. If someone owned the resources, the price he would charge for its use in order to maximize his return would yield a level of output at which social marginal cost was equal to price; alternatively a cartel of firms using the free-access resource would maximize profits by internalizing the external technical diseconomies that firms impose on one another, reducing output until social marginal cost was equal to price. $41 /$ Similarly, the only reason why competitive private enforcement yields a larger output than monopolistic private enforcement at the same fine is that in the former case no one has a property right in offenses (save as acquired on a first-come first-served basis). If instead the state owned the initial rights to all offenses (analogous to ownership of the formerly free-access resource) and auctioned them off to private enforcers, it can be shown that the profit-maximizing fee for each apprehension and conviction, given a fine equal to $f_{0}$, would equal the difference between marginal and average cost at $A_{0}{ }^{*}$ in Figure 4 . Thus, competitive enforcement, combined with the initial ownership of offenses by the state (or by a private firm), 
would yield an output of $A_{0}{ }^{*}$, the same output the monopolistic enforcer would produce. $42 /$ However, the fee charged by the state is equivalent to a tax on the enforcer's output, and since this "tax" creates a discrepancy between the amount offenders pay and the amount enforcers receive, it provides incentives for bribery and corruption (see next subpart).

Another possible system of property rights in legal claims would be to assign them to the victims of offenses. $43 /$ The victim who had the exclusive right to prosecute the offender could attempt to apprehend and convict the offender himself, or hire private enforcers, or sell his right to an enforcer, or refrain from enforcement. As a first approximation, victim enforcement (assuming a large number of victims and profit-maximizing behavior) would produce a level of apprehensions and convictions somewhere between $A_{0}$ and $A_{0}$ * in Figure 4. Victim enforcement eliminates the external diseconomies associated with the duplication of effort and costs when several enforcers pursue a single offender; but no victim has a sufficiently large share of the market to internalize the negative response of offenders to his enforcement activity. 44 However, this is only a partial analysis. We have seen that private monopolistic enforcement (or vesting all rights initially in the state) results in a level of enforcement that maximizes the private return to enforcement. It follows that a firm which acquired all victims' rights would be able to offer each victim a higher price than he could expect to obtain from any other enforcement alternative--so all the rights would be acquired by a single firm. It, need not do all, or any, of the actual enforcing itself--it may resell the rights to enforcers or require them to pay it a "royalty" for each offender convicted--but in any event the price per offender will be set at a level at which some offenses are not 
prosecuted that would be prosecuted under a system of competitive enforcement of victim rights.

This is not to say that the equilibrium condition of every market (absent an antitrust law) is monopolistic because the assets of the industry would be more valuable in the hands of a single firm which could charge a monopoly price. In an ordinary market, the charging of a monopoly price induces new entry and this prospect reduces the expected profits of monopolization, often to the point where they are lower than the expected profits of competitive operation when the costs of obtaining the monopoly are taken into account. There is no threat of entry into the enforcement market,since (abstracting from the problem of the fabricated offense, discussed later) firms are not free to produce offenders. The right to operate in the enforcement market is limited to the victims of offenses, and the number of offenses prosecuted is controlled by the single enforcer who acquires all of the victim rights.

To summarize, if property rights to offenders are acquired by the state (or by a private monopoly) and then sold at profit-maximizing prices to enforcers, competitive enforcement will lead to the identical solution as enforcement by a monopolist (see Figure 5). Thus, the economic function of this form of property rights is to produce a lower social loss from crime [_....... than competitive enforcement without these property rights. Victim property rights without the sale of those rights to a single (i.e., monopoly) enforcer would lead to a partial internalization of the external diseconomies produced in the absence of any property rights. The curve relating $p$ to $f$ in Figure 5 would presumably lie between $P_{2}$ and $\mathrm{PR}_{1}$, and hence the social loss with victim enforcement would be less than the social loss in the absence of property rights but greater than the 
social loss when property rights are assigned to the state or are acquired by a single enforcer. In all our examples of private enforcement, however, excessive enforcement results. This occurs because at the equilibrium position in Figure 5, whatever the private enforcement scheme, the social loss indifference curve is positively sloped; so one can always find a lower $p$, holding $f$ constant, that yields a lower social loss.

A different sort of problem that a system of awarding rights to enforcers on a first-come first-served basis creates is allowing the offender to nullify the deterrent effect of the law by turning himself in and receiving the fine or bounty to which an enforcer is entitled. The payment of the fine to himself washes out the penalty and allows him to retain the proceeds of the unlawful act without bearing any punishment cost. This abuse of the private enforcement concept could in principle be prevented either by disentitling offenders to compensation as enforcers or by granting exclusive rights to enforce the law to victims of offenses, but neither solution would be free from practical difficulty. It would be hard to prevent the offender from hiring an enforcer as his agent to turn him in and receive the reward, or, in a system of victim rights, from using the hired enforcer to purchase the enforcement right from the victim (without disclosure, of course, that the enforcer was acting on behalf of the offender).

The simplest way of dealing with this problem would be to give the victim of the offense the right to claim, either from the enforcer or from the offender, the value of any property taken from him, or damaged, by the offender. But this solution is not wholly adequate. The difficulty lies in the fact that the offender is usually in a position to preempt any other 
enforcer: if he gets wind that an enforcer is closing in on him, he can turn himself in first, and obtain the reward. This possibility may enable offenders to nullify the effects of enforcement, even when restitution to the victim is required and is effective. Consider the following example. The value of the property taken by the offender is $\$ 10$, the probability of apprehension and conviction is .01 , and the punishment is $\$ 1000$. The offender knows that if he commits 100 offenses, he is likely to be punished once; and assume that when apprehension is imminent, he can always turn himself in first and obtain the reward. Then the effective punishment for the offense is not $\$ 1000$, but $\$ 10$ (the required restitution), and the expected punishment cost per offense is not $\$ 10$, but 10 cents.

\section{Taxation of Enforcers}

In principle, one could devise a system of taxes on enforcers, combined with a system of property rights, that would induce enforcers to reduce their activity to a level at which $p$ would lie along the $\partial L / \partial p=0$ curve. $\underline{45 /}$ The tax would shift the demand curve as perceived by the enforcers to the left without reducing $f$ and thereby impairing the deterrent effect of the 1 aw. However, the tax would drive a wedge between what offenders paid and what enforcers received and thereby create attractive opportunities for bribery and corruption, for both the apprehended offender and the enforcer would be better off privately negotiating a payment that was less than the statutory fine but greater than the fine minus the tax. A major criticism of public enforcement advanced by Becker and Stigler, that it creates incentives for bribery and corruption because the gain to the enforcer from enforcement is generally less than the offender's potential penalty, $\underline{46 /}$ might no longer be a strong argument for private enforcement (depending on the size 
of the tax) if enforcers were taxed in order to reduce the level of enforcement to the optimum level. The distinction between private and public enforcement would become blurred in another sense--the character and effectiveness of private enforcement would become dependent, in part at least, on a form of public intervention, albeit a milder form than regulation or public ownership.

Two further points need to be made about the bribery problem created by taxation of enforcers. First, that problem is less acute if rights are assigned on a first-come first-served basis. An offender would be reluctant to bribe an enforcer since the bribe would not buy him absolute immunity from punishment--any other enforcer would be perfectly free to institute proceedings against the offender. However, the first enforcer would sometimes have a "corner" on the information incriminating the offender, in which case the probability of a second enforcer's apprehending the offender would be slight.

Second, a tax on any transaction creates a potential for bribery--an employee has an incentive to bribe his employer (by rebating a portion of his wages) not to withhold a portion of his wages for payment of federal income tax--yet we do not ordinarily assume that the possibility of bribery is a serious objection to using taxes to collect revenues. This is partly because there appear to be no good alternatives, and partly because bribery itself can presumably be deterred by appropriate penalties--and is, indeed, a criminal offense. $47 /$ Assuming bribery of enforcers could be prevented effectively and at moderate cost by being penalized, $\underline{48 /}$ we may not have to worry very much about the incentives to commit bribery that a tax on enforcement would create--but by the same token the problem of bribery would become a less compelling criticism of public enforcement. 


\section{Imprisonment and Other Nonmonetary Sanctions}

The incentive to commit bribery is also present once we relax the unrealistic assumption that an optimal system of penalties would consist solely of fines. When imprisonment and other sanctions that are not a simple transfer payment from offender to enforcer are introduced, it becomes necessary for the state to offer bounties to enforcers if there is to be adequate incentive for private enforcement. $49 /$ Assuming that the optimum system of penalties continues to involve a combination of severe penalties with low probabilities of apprehension and conviction--a realistic assumption even though increases in the penalty can no longer be assumed to be costless--a bounty that is the precise monetary equivalent of the costs of the penalty to the offender will induce excessive enforcement, as enforcers pour resources into apprehending and convicting offenders and raise $p$ above its (low) optimal level. If, however, the bounties are set below $f$ so as to reduce enforcement to the optimal level, there will be a gap between the cost of punishment to the offender and the gain to the enforcer, and opportunities for bribery and other corruption will be introduced. The problem may, however, be less severe than it would be under a system of fines only. The bounties, even though smaller than the cost of punishment to the offender, may exceed his ability to pay since it is the limitations on offenders' resources that require reliance on nonpecuniary penalties in the first place.

\section{E. Errors in Enforcement}

In developing a model of private enforcement in Part I, we unrealistically assumed that enforcement operated without any mistakes. Once that assumption is abandoned it becomes apparent that an enforcement industry, whether public 
or private, has two outputs, the conviction of the guilty and of the innocent. The second has a negative social value. Even when the penalty imposed upon the convicted defendant is a pure transfer payment, the resources consumed in the prosecution are wasted from a social standpoint; 50/ the deterrent effect of the law is also impaired. 51/ Is the output of this social bad--convictions of innocent people--likely to be greater or smaller under private enforcement than under public enforcement?

The private enforcer is paid per offender convicted, regardless of the actual guilt or innocence of the accused. There are several ways in which the enforcer can increase his "catch," and hence his income, by augmenting the supply of "offenders." (1) He can fabricate an offense. $22 /$ (2) He can prosecute an innocent person for an offense that in fact occurred. (3) He can encourage an individual to commit an offense that he would not have committed without encouragement, and then prosecute him for the offense; this is the practice known as "entrapment." (4) knowing that an individual is about to attempt the commission of a crime, the enforcer can wait until the crime has been committed and then prosecute him rather than apprehend him in the attempt stage and prosecute him for a criminal attempt. The incentive for waiting to obtain greater compensation, since the penalty for the completed crime will presumably be heavier than the penalty for the attempt. $53 /$

These abuses would doubtless occur under any system of private enforcement 54 but how frequently? The first two involve the prosecution of an innocent person, and in general we would expect expenditures by the party whose claims are true to be more productive than the other party's expenditures; hence expenditures on trying to "frame" an innocent person would

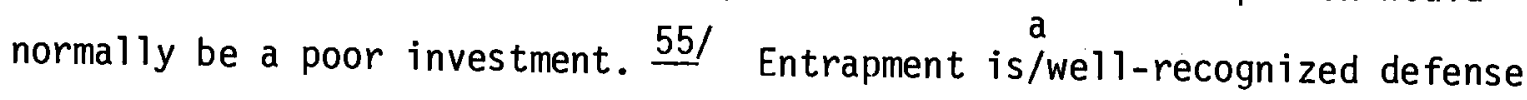


to a criminal charge, so a prosecution based on entrapment would rarely be a valuable use of the enforcer's resources. $\underline{56 /}$ As for the enforcer who stood by and allowed the completed crime to occur, he would have to reckon with the possibility that someone else might apprehend and convict the criminal--especially under a system where the property right to a legal claim was vested in the victim of a crime. $\underline{57 /}$

In any event, the same abuses can and do arise under public enforcement-indeed, the constitutional rules against entrapment, knowing suppression of evidence favorable to the accused, etc., were developed to prevent the commission of these practices by public enforcers--and there is no good theoretical or empirical basis for expecting them to be more widespread under a system of private enforcement. True, the private enforcer is compensated on an explicitly piecework basis, and the public enforcer is not. This may make it more likely that the public enforcer would attempt to maximize deterrence rather than merely the number of convicted offenders weighted by the penalty (net of the costs of enforcement). $\frac{58 /}{}$ The other side of the coin, however, is that the private enforcer may be more sensitive to the costs of the unsuccessful prosecution, and we have indicated why the costs of successfully prosecuting innocent people will often be very high.

Are inadvertent errors likely to be more or less frequent under private as compared to optimum enforcement (or public enforcement, if we assume that the enforcement level is more nearly optimum under public enforcement)? Disregarding deliberate error, we may assume that a given fraction $59 /$ of all enforcement proceedings, either public or private, terminates in the conviction of an innocent person, and ask whether there are likely to be more 
enforcement proceedings under private than under public enforcement and, if so, whether it follows that the aggregate error costs will be higher under the former system.

Assuming the legislature has set the optimal fine-- $f_{1}$ in Figure 5-given the constraint of private enforcement. The resulting probability of apprehension and conviction, $p_{1}$, now includes the conviction of innocent as well as guilty persons. 60/ Since optimal public enforcement at $f_{1}$ would occur at a lower $p$ (along the $\partial L / \partial p=0$ curve), the number of innocent persons convicted would be lower under public enforcement, provided that the elasticity of offenses with respect to a change in $p$ was less than unity. 61/ While the number of erroneous convictions will thus be higher under private enforcement, the social cost of each error will be lower since the optimal penalty is higher under public enforcement. (In Figure 5, social cost is minimized under public enforcement by setting the fine equal to $f^{*}$, and $f^{\star}>f_{1}$, the optimal fine under private enforcement.) To be sure, the optimal $p$ is also lower at $f^{\star}$ than $f_{1}$, but if offenders are less sensitive to changes in $f$ than to changes in $p$ (i.e., $\varepsilon_{f}<\varepsilon_{p}<1$ where $\varepsilon_{f}=0_{f}(f / 0)$ ), the increase in $f$ may be significantly greater than the reduction in $p$, resulting in the imposition of greater aggregate costs on innocent persons under public enforcement.

In sum the social costs of legal error may be no greater (or smaller) under private than under optimum public enforcement. Therefore, a model such as that developed in Part I which ignores legal error may still be quite useful in differentiating private from optimum public enforcement. 
II I. CONTRASTING APPROACHES TO THE ECONOMIC ANALYSIS OF PRIVATE ENFORCEMENT Our conclusion that the market cannot be depended upon to optimize law enforcement will not come as a surprise. Economists have long assumed that a regime of private enforcement would founder either because of freerider problems or because of economies of scale. But it is important to note that ours is not the conventional reasoning. We agree that, in a system of private enforcement where victims purchased the services of enforcers, there would be a free-rider problem: nonpurchasers would benefit from the reduction in illegal activities brought about by the hired enforcers. However, the free-rider problem does not arise under systems of private enforcement in which enforcers purchase rights from victims, or from the state, or acquire rights by apprehending and convicting an offender. The reason is that in these systems the return to enforcement is a fine, whereas under a system in which enforcers are precluded from receiving fines the return to enforcement must come from those buying protection. 621

There appear to be substantial economies of scale in some areas of law enforcement. If the collection of federal taxes were privatized, it seems unlikely that the market would have room for more than one Internal Revenue Service, albeit other sorts of taxes could be (and historically sometimes have been) farmed out for collection to private enforcers. Just as running two sets of telephone lines down the same street is wasteful, so having two enforcers audit the books of the same taxpayer would be wasteful. Two FBI's, or two police departments in the same city, would create similar problems of uneconomical duplication.

It might seem that if enforcement would often be produced under conditions of natural monopoly, the case for public enforcement would be strengthened because private monopolies are not clearly preferable to public 
ones. However, one of the social costs of monopoly--the misallocation resulting from the monopolist's restriction of output--is a social benefit in the enforcement context since, as we have shown, monopoly enforcement reduces the net social loss from illegal activity. A second cost of monopoly--the expenditure of resources to acquire a monopoly--may or may not be substantial in the enforcement context. If the state grants an exclusive franchise under the usual "public convenience and necessity" criterion, the franchisee will receive a valuable asset; firms will compete for this asset, spending real resources such as lawyers' and lobbyists' time; 63 and the total costs of trying to obtain the franchise may (assuming there are no rents in the procuring of franchises) be as great as the value of the franchise. If, however, monopoly came about as a result of the activity of a firm in buying up victim rights, rather than obtaining a franchise, the social costs would be lower. Monopoly rents that might otherwise be used to purchase inputs into the acquisition of a franchise would be exhausted in payments to victims for their rights to offenses. Some costs would result from duplication in soliciting victim rights, but these costs might be no greater than the usual costs of competing for new cus tomers.

We conclude that neither free-rider problems nor economies of scale provide a compelling basis for public law enforcement. But clearly there is more work to be done on this question. It is at least suggestive that the economies of scale in enforcement appear to be concentrated in the investigative phase of enforcement (patrolling, auditing, etc.) and that many of the traditionally "private law" areas of law, such as torts and contracts, do not require much investigation. The victim of an accident knows that he has been injured and, ordinarily, who did it. The same is 
true of breaches of contract. No permanent investigative apparatus corresponding to a public utility's plant is needed in these areas, and this may be part of the reason why they have been left to private enforcement.

\section{POSITIVE IMPLICATIONS OF THE MODEL}

A. The Choice Between Public and Private Enforcement:

A major positive implication of our model relates to the different mixture of public and private enforcement in criminal and other traditional "public law" areas, on the one hand, and tort, contract, and other traditionally "private law" areas on the other. With few exceptions, there is a public monopoly--more precisely a series of public monopolies--of criminal-law enforcement: a private individual may not prosecute for murder, or theft, or the possession of marijuana, or statutory rape. 64/ Often, to be sure, the same act is both a crime and a tort (the crime of theft, for example, is the tort of conversion), and then private enforcement is possible in principle. But if the offender is judgment-proof, as is so often the case with criminal offenders, the tort remedy is ineffectual and the public enforcer has a de facto monopoly. In contrast, in areas of the law such as contracts and torts (excluding those torts that are also crimes) the main burden of enforcement falls on the private sector. Breaches of contract, and torts, are not investigated or prosecuted by the state. The state's role is limited to furnishing the court system. 65/

In terms of our model, the essential difference between crimes, on the one hand, and torts and breaches of contract, on the other, is that with very small resources devoted to apprehension, the probability of 
apprehension tends to be much less than one in the former case, and to approach one in the second. The victim of a breach of contract knows who breached it; the victim of an automobile accident usually knows the identity of the other driver; $66 /$ but the victim of a burglary does not know the burglar's identity. Where the probability of apprehension and conviction is unity, it can easily be shown that the penalty that minimizes the social loss from unlawful activity is equal to the sum of the costs of the harm inflicted by the activity and of the costs of enforcement. 67/ Thus, assuming that $\mathrm{p}$ is approximately unity in the average tort or contract case, the problem of overenforcement discussed in Part I cannot arise. It arose because, in a case where substantial resources are necessary to generate a substantial probability of apprehension, those resources can be saved by setting a very high $f$, but the high $f$ induces private enforcers to expend resources on apprehension--the resources that the high $f$ was intended to conserve. If $p$ is already unity, private enforcers will not expend any resources on trying to increase $p$ any further.

A problem would remain if property rights were assigned to enforcers on a first-come first-served basis rather than to the victim of the tort or breach of contract. For example, if the marginal harm inflicted by the offender's conduct were $\$ 9$ and the marginal costs of apprehension and conviction were $\$ 1$, and hence $f=\$ 10$, the enforcer who was the first to stake his claim would receive a rent of $\$ 9$. The opportunity to obtain such rents might lead enforcers to stake claims simultaneously, to duplicate enforcement costs, or to engage in other methods of spending (e.g., bribing the official in charge of recording claims) that consumed resources. $68 /$ Thus, enforcement on a first-come first-served basis would induce expenditures 
on enforcement in excess of $\$ 1$. Victim rights eliminate this source of waste.

Thus our model predicts--and we in fact observe--greater reliance on private enforcement in areas such as tort, contract, property, and commercial law, where $\mathrm{p}$ approaches unity and victim property rights are practicable (i.e., the cost of enforcing an individual claim is low relative to the value of the claim). The criminal area presents the opposite extreme, especially in "victimless" crimes such as tax evasion and prostitution or "inchoate" crimes (various types of attempt). Most criminal acts are concealable, which means that unless substantial resources were devoted to enforcement $p$ would be much smaller than unity; and the cost of enforcement to the victim--if there is a victim--is high because the average criminal offender is judgment-proof. Private enforcement of the criminal law would require the institution of a comprehensive public bounty system, and any divergence between the bounty and the cost of punishment would create problems. $69 /$

To repeat an earlier point, we are not arguing that private criminallaw enforcement is in fact less efficient than public. However, the fact that society has left enforcement to the private sector in areas where private enforcement is clearly optimal is consistent with the view that the design of our legal institutions has been heavily influenced by economic considerations, and the fact that it has tended to reject private enforcement in those areas where private enforcement is not optimal, and might not be superior to public enforcement, may also be consistent with such a view of legal institutions. $70 /$ 


\section{B. The Assignment of Property Rights in Legal Claims}

A system of law enforcement is implicitly a market in legal claims, and like other markets cannot function efficiently unless there are exclusive rights to the goods in the market, the claims. Although the legal system does not characterize the matter in these terms, there are in fact exclusive rights in claims. The victim of an alleged violation of law has the exclusive right to bring suit to redress the violation (we are abstracting now from public enforcement). He sells that right to the defendant when the case is settled out of court. If the case is litigated, and the defendant wins, the plaintiff's legal claim is extinguished under the doctrine of res judicata; if the plaintiff wins, the doctrine is invoked to prevent relitigation of the same issue between the same parties--i.e., to prevent the (coerced) purchase of the plaintiff's claim by the defendant from being undone.

In some cases the cost of enforcement is so high relative to the value of the claim that the legal-claims "market" would not work if the principle that the victim had the exclusive right to the claim were adhered to strictly. A good example is a price-fixing conspiracy that imposes a small cost on each member of a large class of buyers. The total social costs of the violation may be high, so that enforcement would be socially efficient, but none of the victims has a sufficiently large stake to be willing to bear the expenses of suit. The consumer class action $\underline{71 /}$ is a device, although an oblique and imperfect one, for overcoming this problem. In effect the property rights normally possessed by the victims of an alleged violation are reassigned to the lawyer for the class. Subject to certain controls (probably rather weak) by the court, the lawyer can transfer the victims' 
property rights--without their consent in any meaningful sense--to the defendant. The proceeds of the transfer are divided between the lawyer and the state $\underline{72 /}$ with little or nothing being paid to the nominal sellers of the claim, the members of the class.

While it makes sense to assign rights on a first-come first-served basis in cases where the costs of enforcement are very high relative to the individual victim's stake, in other cases exclusive victim rights would appear to be a more efficient assignment of property rights; and this, roughly is the pattern we observe in the real world. A first-come first-served system would involve at least two problems besides that of external technical diseconomies which we discussed in Part II. The first is the problem of appropriability. Enforcer A begins an investigation of violator $X$, collects extensive information, and is prepared to file suit when enforcer $B$, having heard about $A$ 's investigation, files suit against $X$ first. $A$ and $B$ are bilateral monopolists, and while $A$ will get something from $B$ for the information he has collected, his gains from the investigation will be smaller than if he had had a secure property right. The problem of appropriability here is very similar to that in the market for - inventions, and for the same reason: in both cases the commodity being produced is information.

A could have solved his problem by filing suit before beginning to investigate. This, however, suggests another problem of a first-come first-served system: excessive rewards. It would be inefficient to confer exclusive enforcement rights, potentially of great value, on people who have merely conceived the possibility of suing somebody for something. 
People would spend their time drafting and filing barebones complaints charging large corporations with violations of various laws, and then sit back and wait for the people with investigative skills and resources to purchase their claims. The investment of resources in drafting and filing would be socially excessive. $\underline{73 /}$

There are techniques for getting around these problems, embodied for example in the patent laws. $\frac{74 /}{}$ These laws could be adapted for use in the market for legal claims, but the result might not be very satisfactory. The patent analogy might prove useful, however, in sorting out claims among enforcers in class-action situations, where the principle of victim rights is and must be largely disregarded. $75 /$

Another reason for preferring the existing system of victim rights is that efficiency sometimes requires that the victim of an unlawful act be compensated therefor. For example, under a negligence system in which the right to seek damages is owned by the victim of a negligently inflicted injury, the traveler at a railroad crossing will take only those precautions that are cost-justified, where the expected accident cost is calculated on the assumption that the railroad is complying with its duties under the negligence standard. The potential victim will not take precautions against accidents that would occur only if the railroad violated its duties--behaved negligently--because the victim of such an accident, being fully compensated for any injury resulting from it, is indifferent to whether it occurs and will incur no cost to prevent it. Suppose, however, that the victim has no right to be compensated if he is injured in a negligently inflicted accident--anyone has the right to sue in respect of that accident and to collect and retain damages from the railroad. The railroad may now have 
an incentive to increase the number of accidents at railroad crossings far above the optimal level. Its aim will be to make crossing a railroad track an extremely hazardous activity. At first there will be many accidents and the railroad will have to pay private enforcers--not victims-substantial judgments. Potential victims, however, not being compensated when injured no matter how negligent the railroad's conduct, will soon begin to take measures to protect themselves from crossing accidents. They may cease to use railroad crossings altogether; they may induce the municipal authorities to build an underpass. The number of accidents will fall and the result will be a reduction in the railroad's costs of accident avoidance that may exceed (even after discounting to present value) the costs of answering to private enforcers in damages for the many injuries negligently inflicted during the initial period of reckless behavior. The elimination of accidents will have been achieved by a method that is socially suboptimal.

There is another way to avoid this problem besides compensating victims, and that is to divorce liability from the infliction of injury. In our example, this would mean imposing speed limits and other forms of direct regulation on the railroad. But that implies additional public enforcement.

As another example of the allocative effects of compensation, consider the consequences if rights to press claims based on breach of contract were obtained on a first-come first-served basis instead of being the property of the victim of the breach. A contract is fundamentally a device for allocating risk. If $A$ promises $B$ delivery on a specified date, this means that $A$ insures $B$ against the risk of delayed delivery. The desire of the parties to place this risk on $A$ would be thwarted if, in the event that $A$ failed to make delivery on the specified date, $C$, a stranger to the contract, could sue $A$ for the breach of contract. $76 /$ 
We note in closing that the existing system of victim rights has several drawbacks. For example, legal claims are not freely transferable. A person injured in an accident cannot sell his legal claim against the injurer to a lawyer or other enforcer. This means that he cannot shift the risk created by the uncertainty of litigation (although he can share it with his lawyer by means of a contigent fee agreement) and assuming that risk aversion is prevalent the result may be underenforcement of legal claims. $77 /$ And current law forbids lawyers to use the corporate form. to obtain capital in the capital markets, so even if they were permitted to buy claims they would find it difficult to finance their purchases.

C. The Public Enforcer's Budget Constraint

Another positive implication of our analysis of private enforcement relates to the fact that the budgets of public enforcement agencies tend to be small in relation to the potential gains from enforcement as they would be appraised by a private, profit-maximizing enforcer. $78 /$ For example, the Internal Revenue Service has repeatedly (but unsuccessfully) argued to its appropriations subcommittee that the Service is operating at a budgetary level where the marginal cost of enforcement is far below the marginal return, measured (as a private enforcer would measure it) by the additional tax revenue that additional expenditures on enforcement would generate. There is some evidence that its argument is correct. $\frac{79 /}{}$ The assumption of a budget constraint would be unrealistic as applied to a private enforcer, for assuming reasonably well functioning capital markets he would be able to finance any enforcement activities where the expected monetary return exceeded the expected costs.

The agency budget constraint is at first glance puzzling. Why isn't the legislature interested in maximizing the expected value of enforcement? 
Why doesn't it, therefore, appropriate additional funds to any agency, such as the IRS, that could use the funds to increase the net yield of enforcement? The puzzle disappears when we reflect that a method of appropriation whereby the level of enforcement of the tax laws was allowed to rise to the level that would be reached under a system of private enforcement.could, according to the analysis in Part I, result in overenforcement. The effect of the budget constraint, in forcing the public enforcer to operate where marginal cost is less than marginal revenue and hence where the probability of apprehension and conviction is less than if profits were maximized, is similar to that of a tax on private enforcement designed to reduce the level of private enforcement to the socially optimal level.

There is, to be sure, an element of private enforcement in the enforcement of the federal tax laws: the government pays informers a reward of up to 10 per cent of any additional taxes collected as a result of the informer's But, tip. /were it not for the problem of overenforcement, it would be difficult to understand why the maximum reward has been set at such a low percentage of the revenues produced. If the objective were to carry enforcement of the tax laws to the point where marginal revenue and marginal cost were equated, a reward greatly in excess of 100 per cent of the additional revenues collected might well be appropriate, since each apprehension resulting from an informer's activity would have some effect in deterring other taxpayers from underpaying their tax. $10 /$ Alternatively, the informer, rather than being given a reward in excess of the amount of tax collected, might be given a reward equal to the additional tax plus any penalties imposed (including the monetary equivalent of the costs to the taxpayer of being imprisoned, 
where that was the penalty imposed). The effect of the 10 per cent ceiling is to reduce drastically the scale that the tax informer industry would attain under a system of pure private enforcement.

\section{Discretionary Nonenforcement of the Law}

A public monopoly of enforcement enables the public enforcer in effect to nullify particular laws, or particular applications of law, simply by declining to prosecute violators. This power appears to be exercised frequently $81 /$ and we attempt here to explain why. Our analysis of private enforcement is relevant to the question since it is clear that enforcer nullification would not be a feature of private enforcement: all laws would be enforced that yielded a positive expected net return.

Both economic theory and simple observation suggest that rules of law are almost always overinclusive: read literally, they forbid some conduct that the legislature or court that formulated the rule did not in fact want to forbid. $\frac{82 /}{2}$ The costs of precisely tailoring a rule to the conduct intended to be forbidden would be prohibitive given the limitations of human foresight and the inherent ambiguities of human language. $\frac{83 /}{3}$ The more particularly the legislature tried to describe the forbidden conduct, the more loopholes it would open up. If enforced to the letter, an overinclusive rule could impose very heavy social costs. Analytically, the effect would be like punishing an innocent person in order to reduce the probability of acquitting a guilty one. To be sure, in an economic analysis the danger of punishing the innocent is not decisive against the use of a particular method of law enforcement; the danger must be traded off against 
the costs of alternative methods that would reduce it. But just as the costs both of convicting the innocent and of acquitting the guilty can be reduced simultaneously (e.g., by increasing the amount of resources devoted to the determination of guilt and innocence), so there is a technique--discretionary nonenforcement--by which the costs of overinclusion can be reduced without a corresponding increase in underinclusion (loopholes). The police overlook minor infractions of the traffic code; building inspectors ignore violations of building-code provisions that, if enforced, would prevent the construction of new buildings in urban areas; air traffic controllers permit the airlines to violate excessively strigent safety regulations involving the spacing of aircraft landing and taking off from airports.

This technique of reducing the costs of overinclusion would be unavailable in a system of private enforcement. Suppose a rule prohibits two activities, and $f_{0}$ is the fine for a violation. The social loss function would then be

$$
L=D_{1}\left(0_{1}\right)+C_{1}\left(0_{1}, p_{1}\right)+D_{2}\left(0_{2}\right)+C_{2}\left(0_{2}, p_{2}\right)
$$

and with $f$ fixed, $L$ would be minimized with respect to $p_{1}$ and $p_{2}$, yielding

$$
\begin{aligned}
& D{ }_{1}+C_{1}^{\prime}+\left(\partial C_{1} / \partial p_{1}\right) 1 / 0_{1 p_{1}}=0 ; \\
& D{ }_{2}+C^{\prime}{ }_{2}+\left(\partial C_{2} / \partial p_{2}\right) 1 / 0_{2 p_{2}}=0 .
\end{aligned}
$$

Suppose the marginal damages from $0_{1}$ are smaller than from $0_{2}$ given an equal number of offenses, and the enforcement costs are identical. Then optimality clearly requires that $p_{1}$ be set lower than $p_{2}$ and that more offenses of type 1 be permitted than of type 2. The marginal damages from $0_{1}$ may be zero (the activity was prohibited inadvertently), in which case the optimal value of $p_{1}$ would be zero. Discretionary enforcement is a way of adjusting to the fixed fine, and reduces the net social loss compared 
to the alternative of aggregating the two offenses together and setting a uniform $p$. In contrast, profit-maximizing enforcers would have no incentive to take account of the difference in marginal damages between the two offenses because both the fine and costs of apprehension and conviction are assumed to be identical for both. If the costs of convicting of $0_{1}$ were higher than of $0_{2}$, perhaps because judges and juries were less willing to convict persons accused of $O_{1}$, then differential private enforcement would also emerge. But the difference in costs of conviction would also enter into (14), implying that the difference in enforcement between $0_{1}$ and $0_{2}$ would be even greater under optimal public enforcement and result in a still lower social cost.

The existence of a public monopoly of enforcement in a particular area of the law is a necessary rather than a sufficient condition of discretionary nonenforcement. A public agency could in principle enforce all of the laws entrusted to its administration. But in practice it cannot, given the budget constraint mentioned earlier. Nothing so far said, however, determines the principle by which the public agency will select its cases. Conceivably it could concentrate its resources on precisely those areas of conduct that had been brought inadvertently within the scope of the statutory prohibition. But this seems unlikely. Capricious public enforcement is not unknown (or even rare) but on what little evidence we have does not appear to be the central tendency of public enforcement. $84 /$ Among other reasons, the annual appropriations hearing affords the legislature an opportunity to assure that the agency has not strayed too far from the intended, as distinct from the enacted, legislative regulations that the agency is enforcing. There is no corresponding check in private enforcement. 
An alternative to discretionary nonenforcement is to permit unlimited private enforcement but rewrite the substantive rules of law to eliminate overinclusion. 85/ This alternative involves costs of two sorts: the cost of drafting a more precise rule, and the cost of failing to prevent the socially undesirable conduct that would be rendered legally permissible by the loopholes that a more precise rule would inevitably create. These costs are reciprocal: the loophole effect can be diminished by more careful drafting, but the additional care is costly. The costs of rewriting rules to make them more precise without creating serious loopholes might exceed the costs of discretionary enforcement.

The legislature may not have to rewrite the law. The courts may refuse to enforce foolish or perverse applications of a statute. There are precedents for judicial refusal to enforce the law, and jury nullification of unpopular laws is an old story. $86 /$ Alternatively, an administrative agency with broad interpretive powers could be interposed between the legislature and the private enforcer, and enforcement permitted only after the agency had issued an interpretation of the relevant statute. However, to give judges, juries, or administrative agencies the power to narrow the application of law is simply to shift discretionary nonenforcement from public enforcement agencies to other official bodies. And if giving courts a discretionary power to decline to enforce the law is tolerable, then the major cost of discretionary nonenforcement by public enforcement agencies can be eliminated without abrogating the public monopoly of enforcement.

We anticipate the objection that our analysis ignores the effect of requiring the private enforcer who fails to prove his case against the alleged violator to compensate the latter for the costs of his defense. 
But compensation is immaterial to our argument. If a statute inadvertently forbids practice $X$, requiring a losing enforcer to compensate the alleged violator may deter the enforcer from proceeding against someone who has committed a practice that is not clearly $x$, but it will not deter him from proceeding against someone who is clearly guilty of $X$, merely because $X$ was not really intended to be forbidden. Private enforcers of antitrust laws bring some suits that would not be brought by public agencies because the suits are unrelated or even contrary to the fundamental purpose of the antitrust laws, although consistent with the vague language of the antitrust statutes and the careless language in many judicial opinions in antitrust cases; 87 and often these enforcers succeed in obtaining large judgments or generous settlements. They would not be deterred by being forced to reimburse winning defendants' legal and other expenses.

A major cost of discretionary nonenforcement arises from its converse, which is selective or discriminatory enforcement. Recent disclosures of the inner workings of the federal government indicate that the tax laws are sometimes enforced more harshly against opponents than supporters of the political party in power, and these examples must be much more common than we know. There are also cases where the law is enforced against all but one competing firm, giving that firm an undeserved (and inefficient) advantage over its competitors. This oppressive and inefficient feature of public law enforcement would be eliminated under a regime of private enforcement. The law would be enforced against everyone who violated it and enforcement would not place a particular firm or individual at an unfair disadvantage. Although the danger of discriminatory enforcement is a serious one, it is somewhat mitigated by judicial doctrines that limit discretionary 
enforcement, $88 /$ and in the criminal area by the power of the jury to acquit a defendant for reasons sufficient unto itself. It has been urged that the doctrines limiting discriminatory enforcement be expanded, 89/ and this might be a good idea, although its implementation would not be costless. $90 /$ The effectiveness of these doctrines would be enhanced by, requiring the losing party in a lawsuit to reimburse the winner's legal expenses--this would at least eliminate that form of harrassment that consists of forcing someone to bear the costs of defending against a groundless lawsuit.

\section{E. Blackmail and Bribery}

Blackmail may be defined as the sale of information to an individual who would be incriminated by its publication, and at first glance appears to be an efficient method of private enforcement of the law (the moral as well as the positive law). The value of the information to the blackmailed individual is equal to the cost of the punishment that the individual will incur if the information is communicated to the authorities and he is punished as a result, and so he will be willing to pay up to that amount 91/ to the blackmailer for the information. The individual is thereby punished, and the punishment is the same as if he had been apprehended and convicted for the crime that the blackmailer has discovered, but the fine is paid to the blackmailer rather than to the state.

Why then is blackmail a crime? A superficial answer is that it results in underdeterrence of crimes punished by nonpecuniary sanctions because the criminals lack the resources to pay an optimal fine. The blackmailer will sell his information to the criminal for a price lower than the cost of punishment if the criminal cannot pay a higher price. This 
problem, however, could be solved by a system of public bounties equal to the cost of punishment (or lower, to induce the enforcement industry to contract to optimal size). Then the blackmailer could always claim a bounty from the state if the criminal was unable to pay a price equal to the optimal fine.

A more persuasive explanation of why blackmail is a crime is that the decision to discourage blackmail follows directly from the decision to rely on a public monopoly of law enforcement in some areas of enforcement, notably criminal law. Were blackmail, a form of private enforcement, lawful, the public monopoly of enforcement would be undermined. Overenforcement of the law would result if the blackmailer were able to extract the full fine from the offenders (say $f^{*}$ in Figure 5). Alternatively, the blackmailer might sell his incriminating information to the offender for a price lower than the statutory cost of punishment to the criminal, which would reduce the effective cost of punishment to the criminal below the level set by the legis lature. 921

Consistently with this analysis, we observe that practices indistinguishable from blackmail, though not called by that name, are permitted in areas where the law is enforced privately rather than publicly because the overenforcement problem is not serious. No one seems to object to a person's collecting information about his or her spouse's adulterous activities, and threatening to disclose that information in a divorce proceeding or other forum, in order to extract maximum compensation for the offending spouse's breach of the marital obligations. A third party is not permitted to "blackmail" the offending spouse (unless the third party is the victimized spouse's agent) because permitting him to enforce the marital contract would 
45.

undermine the assignment of the exclusive right to enforce such contracts to the victim of the breach. It is also consistent with our anlaysis that blackmail is forbidden in areas where there are no legal prohibitions at all-where the information would humiliate, but not incriminate, the blackmailer's victim. The social decision not to regulate a particular activity is a judgment that the expenditure of resources on trying to discover and punish it would be socially wasted. That judgment is undermined if blackmailers are encouraged to expend substantial resources on attempting to apprehend and punish people engaged in the activity.

Blackmail and bribery appear to be virtually identical practices from the standpoint of the analysis of private enforcement. The blackmailer and the bribed official both receive payment in exchange for not enforcing the law. We therefore predict that in areas where there is a public monopoly of enforcement, bribery, like blackmail, will be prohibited, while in areas where there is no public monopoly it will be permitted. And so we observe. The settlement out of court of a tort or contract or private antitrust case is a form of perfectly lawful bribery, al though the term is not used in these situations (except by economists) because of its pejorative connotation.

An interesting example of "bribery" occurs in connection with the class action. As mentioned earlier, concern is frequently expressed that the lawyer for the class will be tempted to "sell out" the class by negotiating with the defendant's lawyer a settlement that will involve a combination of nominal relief in favor of the class with a large legal fee for its lawyer; the individual class member's stake in the outcome of the action is too small to warrant his exercising effective control over the lawyer 
for the class. This problem would not arise if the lawyer for the class were permitted to retain the entire proceeds of the class action; then his interest would be identical with that of the class. Such a solution, which is advocated by Becker and Stigler, is simply a specific application of the principle of pure private enforcement, where the entire penalty imposed on the offender is received by the enforcer as compensation. Under existing law, the lawyer for the class is not entitled to receive the entire damages awarded to the class. He is entitled only to a reasonable attorney's fee, which is fixed by the court, ordinarily as a small fraction of the total damages. The difference between the total damages awarded and the attorney's fee is the equivalent of the enforcement tax that we have discussed as a device for reducing the scale of private enforcement. Like the tax, it drives a wedge between what the offender pays and what the enforcer receives, and thereby creates opportunities for a form of bribery, very difficult to prevent, that consists of the offender's agreeing to a settlement that involves a higher attorney's fee for the enforcer, but a lower damages bill, than the court would award. In this fashion both parties to the class action can be made better off--viewing the lawyer for the class as the real party in interest on the plaintiff's side of the action. 


\section{APPENDIX}

\section{Hiring Private Enforcers by Offering Rewards}

A common method by which the victim of a crime or other unlawful activity hires private enforcement is by offering a return for the loss of stolen property. 93/ Rewards are an interesting counterpart to the analysis of private enforcement in Part I. There the "reward"-- in effect, the fine--was a coerced transfer set by the state whereas the typical reward is a voluntary payment determined by a private individual or firm. To simplify the analysis of rewards we provisionally assume that rewards have no impact on the volume of stolen or lost property. $94 /$ Rewards (B) wi11, however, tend to increase the probability (p) that the property is returned to the owner, as in

$$
p=p(B)
$$

where $p^{\prime}=\partial p / \partial B \geq 0$. Let $V$ denote the value of the property to the original owner while $\mathrm{kV}(k \leq 1)$ denotes the value to the finder or thief. $95 /$ In the case of (unmarked) currency, $k$ will approach unity. In the case of goods with high sentimental value or low marketability, for example pets and kidnap victims, $k$ will be close to zero. A reward will be ineffectual when it is less than $k \cdot V$. Thus

$$
p^{\prime}=0 ; B \leq k V
$$

and

$$
\mathrm{p}^{\prime}>0 ; \mathrm{B}>\mathrm{kV} \text {. }
$$

The offeror of the reward will seek to maximize

$$
\Pi=p(V-B)
$$

with respect to $B$, which yields

$$
B=V /\left(1+\frac{1}{\varepsilon}\right) \text {, }
$$


providing $\mathrm{p}^{\prime}>0$ and where $\varepsilon=\mathrm{p}^{\prime}(\mathrm{B} / \mathrm{p})$. 96/ (Obviously when $\mathrm{p}^{\prime}=0$, no reward is offered.) $B$ will be a positive function of both $V$ and the elasticity of response to changes in $B$. Further, the smaller $k$ is, the more likely is it that $B$ will exceed $k V$ and that a reward will be offered. $97 /$

The legal rules governing rewards are given by the branch of the law of contracts dealing with so-called unilateral contracts. For example, suppose $A$ posts a reward for information leading to the arrest of $X$ and the recovery of $A$ 's property stolen by $X$. If $C$, having learned of the reward, complies with the conditions set by $A$, he has a legal right to claim the reward--to enforce, in other words, A's "unilateral contract". But suppose $C$ finds $X$ and returns $A^{\prime}$ 's property to him without having known of the reward. In this instance $C$ has no legal claim to the reward. $\underline{98 /}$ It is interesting to examine what effect this rule has on $p$ and $B$ compared to an alternative that compels the payment of the reward without inquiring into whether or not $C$ had knowledge of its existence. In the latter instance, the incentives of some enforcers to invest time and effort in learning about and following through on reward offers will be reduced if they know that the casual finder is now more likely to return lost or stolen property knowing that if there is a reward he is entitled to claim it though he was unaware of its existence. Granting legal rights to the "casual" enforcer, therefore, reduces $\varepsilon$, the elasticity of response of $p$ to a change in $B$, by its discouraging effect on the more serious enforcers.

The result of the right will be to induce the posting of lower rewards (see (21)). 99/ It does not follow, however, that the level or amount of enforcement will fall: the increased incentive of the casual enforcer may more than offset the reduced incentive to the serious enforcer and hence $p$ will rise. 


\section{Footnotes}

* Professor of Economics, University of Chicago Law School; Senior Research Staff, National Bureau of Economic Research.

** Professor/Law, University of Chicago Law School; Senior Research Associate, National Bureau of Economic Research.

Our research has been supported by a grant from the National Science Foundation to the National Bureau of Economic Research for the study of law and economics. This is not an official National Bureau publication, however, because it has not yet undergone the full critical review accorded National Bureau publications, including approval by the Bureau's Board of Directors. We are grateful to the participants at the Industrial Organization and Law and Economic Workshops of the University of Chicago, the Summer Workshop at the National Bureau of Economic Research-West, and the Law and Economics Workshop of Cornell Law School, for helpful comments on earlier drafts of this article.

1. See references in Richard A. Posner, Economic Analys is of Law, pt. VI (1973).

2. Law Enforcement, Malfeasance, and Compensation of Enforcers, $3 \mathrm{~J}$. Leg. Studies 1 (1974).

3. They would provide a perfect parallel to private enforcement if violators of law were assumed to be nondeterrable--a belief common in certain criminological circles. 
4. See 2 Leon Radzinowicz, A History of English Criminal Law and Its Administration from 1750 (1957); Margaret Gay Davies, The Enforcement of English Apprenticeship, A Study in Applied Mercantilism, 1563-1642 (1956). Although there were some public police, they were paid only nominal salaries by the state, and looked to bounties, fines, and the like as their principal compensation--in effect they were 1 icensed private enforcers.

The history of private criminal-law enforcement in the United States has not, to our knowledge, been studied extensively. Evidently, there was some borrowing from the English model. For example, the Refuse Act of 1899 provides that one-half of the fine for a violation of the Act is to be paid "to the person or persons giving information which shall lead to conviction." 33 U.S.C \$ 411 (1970). However, the statute has recently been construed as placing the exclusive authority to bring enforcement actions in the Department of Justice. See Bass Angler Sportsman Society v. United States Steel Corp., 324 F. Supp. 412 (D. Ala. 1971), aff'd sub nom. Bass Angler Sportsman Society v. Koppers Co., 447 F.2d 1304 (5th Cir. 1971).

5. See Richard A. Posner, Economic Analys is of Law (1973), for a discussion of the positive economic theory of law and references to supporting studies. Cf. The Economics of Crime and Punishment (Gary S. Becker \& William M. Landes eds. 1974).

6. We ask the nonmathematical reader not to be deterred by the formal development of the model in Part I, and by the occasional references to the formal model thereafter. We provide a 
6 continued

verbal explanation of the principal features of the model and the findings based on it.

7. A more complicated model would consider apprehensions and convictions separately, and thus allow, for example, for enforcement by harrassment (arresting and/or prosecuting but not convicting an offender).

8. The model does not distinguish between offenders and offenses: each offender is assumed to commit a single offense. The number of offenses is included in the industry's production function for the following reason. To produce an apprehension and conviction, a criminal offense will generally have to occur and hence an offender will have to exist (the special case of the fabricated offense is treated in Part II E infra). As the number of offenders increases, both the resources expended in searching out an offender and the waiting time between offenses will typically decline and hence the number of apprehensions and convictions will increase for a given input of hired resources. An appropriate analogy is to an industry consisting of firms fishing on a lake, where a given output of fishing resources will yield a greater catch, the greater the number of fish in the lake.

9. We make one assumption not explicit in the Becker-Stigler analysis: that the offender is not entitled to turn himself in and receive the fine. The importance of this assumption is discussed in Part II B infra. 
10. Defining $\lambda \equiv 1 / 0,(1)$ can be rewritten as $A=O A(R / 0,1)=0 p$, where $A / 0=p$. Since the marginal product of $R$, which equals $0(\partial p / \partial(R / 0))$ $\partial(R / 0) / \partial R=\partial p / \partial(R / 0)$, is assumed to be positive, $p$ is a positive function of $R / 0$.

11. See Gary S. Becker, Crime and Punishment: An Economic Approach, 76 J. Pol. Econ. 169 (1968); Isaac Ehrlich, Participation in Illegitimate Activities: A Theoretical and Empirical Investigation, 81 J. Pol. Econ. 521 (1973), and The Deterrent Effect of Criminal Law Enforcement, 1 j. Leg. Studies 259 (1972).

12. The similarity of this analysis to that of a free-access resource should be apparent. See F. H. Knight, Some Fallacies in the Interpretation of Social Cost, reprinted in Readings in Price Theory (George J. Stigler \& Kenneth E. Boulding eds. 1952); see also Steven N. S. Cheung, The Structure of a Contract and the Theory of a Non-Exclusive Resource, 13 J. Law \& Econ. 49 (1970); J. R. Gould, Externalities, Factor Proportions and the Level of Exploitation of Free Access Resources, Economica (1972). In Knight's example of the well-graded but narrow road, trucks entering the road ignore the added congestion costs imposed on other trucks. In the enforcement case, firms entering the industry or expanding ignore the resulting reduction in the number of offenders available to other firms. Both cases are examples of external technical diseconomies and lead to upward shifts in the marginal cost curves of firms. 
12. continued

Competitive enforcement might also generate external economies. Suppose enforcer $X$ apprehends an offender who has committed additional offenses not known to $X$ but known to enforcers $Y$ and $Z$. $X$ 's activity will have lowered the costs to $Y$ and $Z$ of apprehending and convicting the offender. This source of external economies is eliminated in our analysis by the assumption that each offender commits a single offense. If this assumption were dropped, our analysis would have to assume that the external diseconomies were greater on balance than any external economies.

13. Equilibrium also requires that each firm maximize profits. Thus marginal cost must equal $f$ for the firm while average cost $(r /(0 / R) p)$ must equal $f$ for the industry. These requirements can be reconciled as follows. Assume the firm's production function with respect to 0 and $R$ is homogeneous of degree one at its equilibrium output. (This would be true even if the firm's cost function were rising or $U$-shaped, because competition would force the firm to operate in the constant part of its average cost curve.) Since the firm by assumption acts as if 0 were freely available at a zero price, it would utilize offenders until their marginal product, as calculated by the firm, were zero. That is, the ith firm would employ 0 until $\partial A_{i} / \partial 0_{i}=p_{i}-p_{i}(R / 0)=0$, which implies $p_{i}(0 / R)=p_{i}^{\prime}$. In other words, the firm acts as if the marginal product of $R$ is equal to the average product of $R$. Hence each firm would view the industry's average product of $R$ in equilibrium as identical to the firm's marginal product, or industry average cost as equal to the firm's marginal cost. 
13 continued

Of course, the industry's marginal product of $R$ is below its (private)

average product, and therefore the firm's/marginal product exceeds (social)

the industry's/marginal product.

14. The average product of $R$ equals $(0 / R) p$ and

$$
\frac{\partial((0 / R) p)}{\partial(R / 0)}=-(0 / R)^{2}\left(p-(R / 0) p^{\prime}\right)<0
$$

where $p^{\prime}=\partial p / \partial(R / 0)$. Since $p-(R / 0) p^{\prime}$ is the marginal product of 0 , which is assumed positive for the industry, $\partial((0 / R) p) / \partial(R / 0)$ is negative. Observe that $p^{\prime}>0$ since $p^{\prime}$ is the marginal product of $R$. Hence $p$ is a positive function of the $R / 0$ ratio while the average product of $R$ is a negative function of this ratio.

15. Since $p$ remains equal to $p_{0}$, the equilibrium increase in offenses is the original exogenous increase of 20 per cent.

16. No social purpose would be served by these devices in our model since by assumption no innocent persons are convicted.

17. This occurs because with $A$ constant at $A_{0}, p$ will rise above $p_{0}$. Hence there will be a movement up the offense function as well as a shift of the function to the left. 
18 The total differential of the equilibrium conditions in equation (5) with respect to $p$ and $f$ yields

$$
0=d f+\left(\frac{r(R / 0)}{p^{2}}-\frac{r}{p p}\right) d p
$$

where $p^{\prime}=\partial p / \partial(R / 0)=\partial A / \partial R>0$. (i) can be rewritten as

$$
\frac{d p}{d f}=\frac{p^{2} p^{\prime}}{r\left(p-p^{\prime}(R / 0)\right)}>0
$$

where $\left(p-p^{\prime}(R / 0)\right)=\partial A / \partial 0>0$ (from the assumption that the marginal product of 0 for the industry is positive).

19. See Gary S. Becker, supra note 11. Total enforcement costs have previously been defined as $r \cdot R$. Since $R$ can be written as a function of 0 and $p$, total enforcement costs can be written as a function of $p$ and 0 . Thus $r R=r R(0, p)=c(0, p)$.

20. For a formal analysis of this point see Michael K. Block \& Robert C. Lind, Crime and Punishment Reconsidered, 4 J. Leg. Studies (1975). Block and Lind also discuss the conditions under which imprisonment beyond some point produces no marginal deterrence.

21. If $D \leq 0$ at this point, the optimum $p$ would be arbitrarily close to zero and the optimum number of apprehensions and convictions would also be approximately zero. The assumption that $D^{\prime \prime}>0$ is taken from Gary S. Becker, supra note 11, at 173. 
22. Suppose $f$ were less than $f^{*}$ and $p$ was finite. A reduction in $p$ matched by an appropriate increase in $f$ would then produce the same deterrent effect--the same number of offenses--at a lower social loss since $C$ would be reduced. Hence $f$ would be raised until it reached $f^{*}$.

23. If the optimal level of offenses were zero, there would be no purpose in analyzing enforcement or comparing private and public enforcement because there would be no offenders to apprehend and no enforcement activity; there would only be some stand-by enforcement capacity to keep $p$ from falling all the way to zero.

24. In the case of competitive private enforcement, form the Lagrangian $L^{*}$ :

$$
L *=L+\lambda[f-r /(0 / R) p] \text {. }
$$

Minimizing $L *$ with respect to $f, p$, and $\lambda$ yields

$$
\begin{aligned}
& \partial L^{*} / \partial f=\partial L / \partial f+\lambda=0 \\
& \partial L^{*} / \partial p=\partial L / \partial p+\lambda\left[r(R / 0) / p^{2}-r / p^{\prime} p\right]=0 \\
& \partial L^{*} / \partial \lambda=f-r /(0 / R) p=0
\end{aligned}
$$

and

$$
\frac{-\partial L / \partial f}{\partial L / \partial p}=\frac{p^{2} p^{\prime}}{r\left(p-p^{\prime}(R / 0)\right)}
$$

We assume that the second-order conditions are satisfired for a local minimum.

25. See the derivation of $\mathrm{dp} / \mathrm{df}$ in note 18 , supra. 
26. We have

$$
D L=(\partial L / \partial f) d f+(\partial L / \partial p) d p=0
$$

which yields

$$
\frac{d p}{d f}=\frac{-\partial L / \partial f}{\partial L / \partial p}
$$

since $d L=0$. The explicit derivation of $\partial \mathrm{L} / \partial f$ and $\partial \mathrm{L} / \partial \mathrm{p}$ must take account of the assumption that the enforcement production function involves constant returns to scale. Since $C(0, p)=r R$,

$$
\begin{aligned}
& \partial L / \partial f=D^{\prime} 0_{f}+r \frac{\partial R}{\partial 0} 0_{f} \\
& \partial L / \partial p=D^{\prime} 0_{p}+r \frac{\partial R}{\partial p}
\end{aligned}
$$

where $0_{f}=\partial 0 / \partial f$ and $0_{p}=\partial 0 / \partial p$. With $p$ constant, $\partial R / \partial 0=R / 0$ and hence ( $i i i)$ becomes

$$
\partial L / \partial f=D^{\prime} 0_{f}+r \frac{R}{0} 0_{f}
$$

$\partial R / \partial p$ in (iv) is more complicated to evaluate where

$$
\left.\frac{\partial p}{\partial R}=p^{\prime}\left(\frac{1}{0}-\frac{R}{0^{2}} 0_{p} \frac{\partial p}{\partial R}\right)=\frac{p^{\prime}}{0\left(1-\tilde{p} \varepsilon_{p}\right.}\right)
$$

It can be shown that $0<\tilde{p}\left(=p^{\prime} \cdot(R / 0) / p<1\right.$ since

$$
\partial A / \partial 0=p-p^{\prime}(R / 0)=p(1-\tilde{p})>0 .
$$

(iv) can now be written as

$$
\partial L / \partial p=D^{\prime} 0_{p}+\frac{r 0\left(1-\tilde{p} \varepsilon_{p}\right)}{p^{\prime}}
$$

We assume that enforcement costs rise as $p$ increases (i.e., $\partial C / \partial p=$ $r \partial R / \partial p>0$ in $(i v))$. This requires that the product $\tilde{p} \varepsilon_{p}$ be less than unity. Since $0<\tilde{p}<1, \tilde{p} \varepsilon_{p}$ will necessarily be less than unity if $\varepsilon_{p}<1$. 
27. As the point where $2 L / \partial p=0$ (given $f$ ), we assume that the secondorder conditions for a local minimum are satisfied, $\underline{i . e .}$, $\partial^{2} L / \partial p^{2}>0$. We can write

$$
\frac{\partial L}{\partial p}=-D^{\prime} \varepsilon_{p}+\frac{r p}{p^{1}}\left(1-\tilde{p} \varepsilon_{p}\right)=0 .
$$

$-D^{\prime} \varepsilon_{p}<0$ and $\frac{r p}{p^{\prime}}\left(1-\tilde{p} \varepsilon_{p}\right)>0$ since $0<\tilde{p}<1$ and $0<\varepsilon_{p}<1$. We take as an approximation that $\varepsilon_{\mathrm{p}}$ and $\tilde{\mathrm{p}}$ are constant. (For example, in the Cobb-Douglas function $A=k R^{\alpha} 0^{1-\alpha}, p$ equals $k(R / 0)^{\alpha}$ and $\tilde{\mathrm{p}}\left(=\partial \log \mathrm{p} / \partial \log (R / 0)\right.$ equals the constant $\left.\alpha_{\text {. }}\right)$ Hence

$$
\frac{\partial^{2} L}{\partial p^{2}}=D^{\prime \prime} 0_{p} \varepsilon_{p}+\frac{r}{p^{1}}\left(1-\tilde{p} \varepsilon_{p}\right)\left[1-\frac{p p^{\prime \prime}}{\left(p^{\prime}\right)^{2}}\right]>0
$$

whenever $D^{\prime} \geq 0$. Note $p^{\prime \prime}<0$ follows from the earlier assumption of diminishing marginal product of $R$ where $\partial^{2} A / \partial 0^{2}=p^{\prime \prime}(1 / 0)<0$. The effect of a change in $f$ on $p$, assuming that $\partial L / \partial p=0$, is given by

$$
\frac{d p}{d f}=\frac{D^{\prime \prime} 0 f^{\varepsilon} p}{\left(\partial^{2} L / \partial p^{2}\right)}<0
$$

provided that $D^{\prime \prime}>0$ and $\partial^{2} L / \partial p^{2}>0$.

28. When $\partial L / \partial p=0$, we have at each $f$

$$
\partial L / \partial p=D^{\prime} 0_{p}+\frac{r}{p^{\prime}}, 0\left(1-\tilde{p} \varepsilon_{p}\right)=0 .
$$

Since $0_{p}<0$ and $\left(r / p^{\prime}\right) 0\left(1-\tilde{p} \varepsilon_{p}\right)>0$ (from the assumption that the marginal cost of increasing $p$ is positive), $D$ ' must be positive for (i) to equal zero. An increase in $f$ will reduce 0 which in turn will reduce both the amount of damages (since $D^{\prime}>0$ ) and the costs of enforcement (since $r$ is ro maintain a constant $p$ ) Hence $\partial L / \partial f<0$. 
29. As $p$ continues to increase along a given SLIC, the number of offenses may be reduced to the point where marginal net damages are negative (i.e., where the net gain to the offenders after deducting the direct costs of committing the offense exceeds the added harm from the offense). Hence, increases in $f$ at this point-working through reducing 0 --may raise the social 1oss, and the SLIC will then fall forward, having a negative slope. This part of the indifference curve, however, is irrelevant (as will become more apparent below) when the social loss is minimized under either private or public enforcement.

30. In Figure 3 we assume not only that an optimum point exists but that it is unique. There are other possibilities. For example, it is likely that $\mathrm{PR}_{1}$ will increase at a decreasing rate and asymptotically approach a limit $(\leq 1)$. Thus, $/$ range, the slope of $\mathrm{PR}_{1}(=\mathrm{dp} / \mathrm{df})$ may decrease at the same rate as $-(\partial L / \partial f) /(\partial L / \partial p)$ so that a range of values for $p$ and $f$ will satisfy the optimality condition. Second, $d p / d f$ may always be less than $-(\partial L / \partial f) /(\partial L / \partial p)$ when the latter is positive and the optimal p will then be at a "corner"--i.e., at a point where the fine equals $f^{*}$.

31. If the fine were set at $f^{*}--$ the value of $f$ that minimizes the unconstrained social loss function--instead of $f_{1}$, both the difference in social loss and the amount of excess enforcement would be even greater under private than public enforcement. Since the minimum social loss with private enforcement is where $p=p_{1}$ and 
31 continued

$f-f_{1}$, the social loss must be greater at $f^{\star}$ along the $P R_{1}$ curve. In contrast, the social loss at $f^{*}$ is less than at $f_{1}$ along the $\partial L / \partial p=0$ curve. Hence the difference in social loss between private and public enforcement must be greater at $f^{*}$ than at $f_{1}$. The difference in probabilities is obviously greater at $f^{*}$ than $f_{1}$ since $\mathrm{PR}_{1}$ is positively sloped and $\partial \mathrm{L} / \partial \mathrm{p}=0$ is negatively sloped.

32. This overenforcement theorem may not hold if the optimal fine under private enforcement is the corner solution $f^{*}$. It is conceivable that $f^{*}$ may be sufficiently small relative to enforcement costs so that the positively sloped $P R_{1}$ curve is below the $\partial L / \partial p=0$ curve at $f^{*}$. Of course, if $f^{\star}$ were sufficiently large relative to enforcement costs, the overenforcement theorem would still hold at the corner. We disregard these possibilities in the subsequent analysis.

33. This explanation should make clear that the overenforcement theorem does not depend on our assumptions that the enforcement industry is competitive and that rights to offenders are acquired strictly on a first-come first-served basis. That is, it does not depend on the analogy between enforcement and the exploitation of a free-access resources. This is shown rigorously in Part II B infra.

34. This result does not require a single monopoly of all enforcement activity in the society. Monopolies of particular types of offenses or in particular areas, are all that is necessary in order to internalize the responses of offenders to enforcement activity, assuming separate markets within the law-enforcement industry. 
35. We assume that $\varepsilon_{p}$, the elasticity of the supply of offenses with respect to a change in $p$, is less than unity. 0therwise, reductions in $R$ (and hence $p$ ) would always raise profits since $A(=0 p)$ would rise $\left(\varepsilon_{p}>1\right)$ or remain constant $\left(\varepsilon_{p}=1\right)$ and costs would fall (as $R$ fell ). Profits would then be maximized by setting $R$ (and $p$ ) at infinitesimally small values. Moreover, if $\varepsilon_{p}>1$ this would result in an arbitrarily large number of both offenders and apprehensions.

The first-order condition for profit maximization is

and

$$
\frac{d I}{d R}=f 0 \frac{d p}{d R}+f p 0 \frac{d p}{d R}-r=0
$$

$$
\begin{aligned}
\frac{d p}{d R} & =p^{\prime}\left(\frac{1}{0}-\frac{R}{0} 20 \frac{d p}{d R}\right) \\
& =p^{\prime} / 0\left(1+\frac{R}{02} p^{\prime} 0 p\right) \\
& =p^{\prime} / 0\left(1-\tilde{p} \varepsilon_{p}\right)
\end{aligned}
$$

Substituting (iv) into ( $i$ ) and rearranging terms yields

$$
\begin{aligned}
\frac{d \pi}{d R} & =f-\frac{r}{\left.p^{\top}\left(1-\varepsilon_{p}\right) K-\tilde{p} \varepsilon_{p}\right)}=0 \\
& =f-\frac{r}{p^{\top} \omega}
\end{aligned}
$$

$\varepsilon_{p}$ has been assumed $<1$, and it has previously been shown that $\tilde{p}$ is also less than unity (see note 26 , supra).

(. Therefore, $\omega$ is less than unity since $0<\varepsilon_{p}, \tilde{p}<1$.

If we assume as a first approximation that $\varepsilon_{p}$ and $\tilde{p}$ are constant, then the second-order condition for a maximum is simply that $\partial p^{\prime} / \partial R<0$, or that marginal cost be rising. $\partial p^{\prime} / \partial R$ must be negative by the assumption that the marginal product of $R$ is diminishing. 
36 Although $r / p^{\prime} \omega$ internalizes the response of offenders to an increase in $A$ via the inclusion of $\varepsilon_{p}$ in $\omega$, there is still only one possible equilibrium point along this curve. An increase in $f$ will reduce the number of offenses, lowering $p^{\prime}$ and shifting the marginal cost curve to the left.

37. At $A_{0}$ the difference between marginal cost and average cost equals $d=r\left[\frac{1}{p^{\top} \omega}-\frac{1}{(0 / R) p}\right]=r\left[\frac{p-(R / 0) p^{\prime} \omega}{p^{\prime} \omega p}\right]$.

Since $p-(R / 0) p^{\prime}=\partial R / \partial 0>0$, and $0<\omega<1, d$ is positive.

38. The proof that $p_{m}<p_{c}$ at $f_{o}$ (where the subscripts $m$ and $c$ denote monopoly and competition respectively) is as follows. The equilibrium conditions (5) and (11) in the text imply that

$$
p_{m}^{\prime}{ }_{m}^{\omega}=p_{c}(0 / R)_{c}
$$

Multiplying the right-hand side of $(i)$ by $\mathrm{p}^{\prime}{ }_{\mathrm{c}} / \mathrm{p}^{\prime}{ }_{\mathrm{c}}$ yields

$$
\mathrm{p}^{\prime}{ }^{\omega}{ }^{\omega}=\mathrm{p}^{\prime}{ }_{\mathrm{c}} / \tilde{\mathrm{p}}_{\mathrm{c}}
$$

where $0<w, \tilde{p}<1$. Therefore, (ii) holds only if $p_{m}^{\prime}>p^{\prime} c^{\cdot}$ And since $p^{\prime}$ is a negative function of $R / 0$ (from the assumption that $p^{\prime \prime}<0$ or that both $R$ and 0 have diminishing marginal products), $\mathrm{p}^{\prime}{ }_{\mathrm{m}}>\mathrm{p}_{\mathrm{c}}{ }_{\mathrm{c}}$ only if the $\mathrm{R} / 0$ ratio is smaller under monopoly than competition, which in turn implies that $p_{m}<p_{c}$.

39. Form the Lagrangian

$$
L^{*}=D(0)+C(0, p)+\lambda\left[f-r / p^{\prime} w\right]
$$


39. continued

Minimizing $L^{*}$ with respect to $f$ and $p$, and assuming as an approximation that $\omega$ is a constant, yields

$$
\begin{aligned}
& \partial L^{*} / \partial f=\partial L / \partial f+\lambda=0 \\
& \partial L^{*} / \partial p=\partial L / \partial p+\lambda\left[r p^{\prime \prime} / \omega\left(p^{\prime}\right)^{3}\right]=0 \\
& \partial L^{*} / \partial f=f-r / p^{\prime} \omega=0
\end{aligned}
$$

and

$$
\frac{\partial L / \partial f}{\partial L / \partial p}=\frac{-\omega\left(p^{\prime}\right)^{3}}{r p^{11}}
$$

We assume that the second-order conditions are satisfied for a local minimum.

40. Using the subscripts $m$ and $c$ to denote monopoly and competition respectively, we have

$$
\begin{aligned}
& d p_{m} / d f=-\omega\left(p^{\prime}\right)^{3} / r p^{\prime \prime} \\
& d p_{c} / d f=p p^{\prime} / r(1-\tilde{p})
\end{aligned}
$$

Assuming as an approximation that $\tilde{p}, \varepsilon_{p}$ and $\omega$ are all constants yields

$$
\begin{aligned}
& \partial A / \partial O=p(1-\tilde{p})>0 \\
& \partial^{2} A / \partial O^{2} \simeq-p^{\prime}\left(R / 0^{2}\right)(1-\tilde{p})<0
\end{aligned}
$$

Since $\partial^{2} A / \partial O^{2}$ also equals $p^{\prime \prime}\left(R^{2} / 0^{3}\right)$, we have

$$
-p^{\prime}(0 / R)(1-\tilde{p}) \simeq p^{\prime \prime}
$$

Substituting (11) and (v) into (i) (and ignoring the approximation sign) and multiplying by $p_{m} / p_{m}$ yields

$$
d p_{m} / d f=p_{m} \tilde{p} / f(1-\tilde{p})
$$

Substituting (5) into (ii) and multiplying by $p_{c} / p_{c}$ yields

$$
d p_{c} / d f=p_{c} \tilde{p} / f(1-\tilde{p})
$$

Since at the same fine $p_{m}<p_{c}$,

$$
d p_{m} / d f<d p_{c} / d f \text {. }
$$


41. This assumes that the price of the output of the free-access resource is independent of the level of output in the relevant range.

42. Total fees $(T)$ for the state would equal

$$
T=f_{0} 0 p-r R
$$

and the fee per apprehension ( $t$ ) would equal

$$
t=f_{0}-r /(0 / R) p .
$$

Thus $t$ is equal to the difference between $f$ and the average cost of a unit of $A$. Maximizing $T$ with respect to apprehensions and convictions and assuming a fixed $f$ yields

$$
\frac{d T}{d A}=f-r \frac{d R}{d A}=0 \text {. }
$$

Now

$$
\frac{d R}{d A}=\frac{1}{p^{\prime}+\frac{d p}{d R} 0_{p}\left(p-p^{\prime} \frac{R}{0}\right)} .
$$

Noting that $p-p^{\prime} \frac{R}{0}=p(1-\tilde{p})$ and making use of the derivation of $d p / d R$ in note 35 supra we derive

$$
\frac{d T}{d A}=f_{0}-\frac{r}{p^{\top} \omega}=0 \text {. }
$$

That is, total fees are maximized at a given fine by charging a price per apprehension equal to the difference between marginal and average cost. Note that the average cost curve in Figure 4 is not the relevant average cost curve at $A_{0}{ }^{*}$ because the number of offenders at $A_{0}{ }^{*}$ will be larger than at $A_{0}$. 
43. A system of de facto victim rights might emerge from a first-come first-served system if enforcers could not prosecute offenders successfully without the victim's cooperation (in signing a complaint, testifying, etc.).

44. If $\varepsilon_{p}$ were equal to zero (i.e., offenses were unresponsive to changes in $p)$, then victim enforcement would be identical to enforcement under a system of state-assigned property rights. Note that when $\varepsilon_{p}=0$, the latter assignment still yields a lower level of apprehensions than the first-come first-served system because marginal cost exceeds average cost $\left(r / p^{\prime}>r / p(0 / R)\right)$ at a given output in Figure 4 . 45. Gary S. Becker \& George J. Stigler, supra note 2, at 16, recognize
excessive private the problem of / enforcement and suggest a tax as a way of overcoming it.

46. See id. at 14 .

47. Even the fact that contracts of bribery are not legally enforceable presumably discourages bribery to some extent. The offender has no legal protection against the enforcer's trying to extract a second bribe from him or selling the incriminating information to a second enforcer. 
47 continued

However, an enforcer who acquired a reputation for double dealing would have difficulty extracting bribes in the future from other people.

48. But it is not clear that it can be. See B. Peter Pashigian, on the Control of Crime and Bribery (U. Chi. Grad. Sch. Bus., Sept. 1974). The size of the tax necessary to bring about the optimum level of enforcement would presumably be an important variable determining the costs of preventing bribery.

49. Lacking as we do the imagination of the Tudors:

Under it [the statute 1 Edw. 6, c. 3 (1547)], a city, town or village which tolerated vagrants and vagabonds might be sued by anybody for a part of the penalty the rest of which went to the Crown. A pauper convicted of 'so living idle and loiteringly' was to be branded with hot irons and given to the informer [i.e., enforcer] as his slave for two years, to be fed on bread and water and caused to do all such work, 'how vile soever it bee, as hee shall put him unto', by 'beating, cheining, or otherwise.'

2 Leon Radzinowicz, supra note 4, at 140. The statute was repealed after two years. Ibid.

50. Expenditures the only purpose and effect of which are to transfer weal th have no social product where, as here, there is no ethical or other socially approved reason for the transfer.

51. See Richard A. Posner, An Economic Approach to Legal Procedure and Judicial Administration, 2 J. Leg. Studies 399, 412 (1973). 
52. This is a familiar problem in an activity analogous to private law enforcement: animal bounty-hunting. There have been cases where, when bounties were offered for coyotes, or other pests, some people would raise these animals for the bounty, or turn in the ear of a dog for the bounty claiming that it was a coyote's ear. See T. S. Palmer, Extermination of Noxious Animals by Bounties in Yearbook of the U.S. Dep't of Agriculture, 1896, at 55, 62-64 (1897).

53. This example raises the interesting question why preparatory activities (attempts) are punished at all--what is the social harm of trying but failing to commit a crime? The conventional explanation in the criminal law literature is that the attempt identifies the individual who commits it as a dangerous person likely to commit the completed crime in the future, and we punish him to discourage or prevent him from doing so. This is not a satisfactory economic explanation for the law of attempts. Under a system of optimal penalties, the expected punishment cost to the criminal--i.e., the price that he must pay to commit the crime--will be exactly equal to its social cost, so if he chooses to commit the crime it will mean that the value of the criminal act exceeds its cost. The commission of a crime when optimal penalties are in effect is no more reprehensible than the purchase of an apple when the price of an apple is equal to the social cost of producing and selling apples. The difference, which suggests an economic rationale for 
punishing (some) attempts, is that the social cost and hence appropriate price of many criminal activities (murders, cartels, etc.) are so difficult to determine that we try to prevent such activities from occurring by intervening at the preparatory stages, rather than allowing the legal system's "market" in cimres to determine their extent.

54. They are much stressed in the literature on the history of private enforcement of the criminal laws in England. See 2 Leon Radzinowicz, supra note 4. But no systematic evidence of the frequency of such abuses appears to be available. One abuse that is mentioned in the literature (see id. at 308) but omitted from our enumeration is collusion between enforcer and offender: the enforcer pays someone to commit a crime, apprehends and convicts him, and then divides the bounty with the offender. This practice will occur only when the penalty is smaller than the reward, and normally (but not invariably; see p. infra) efficiency will require that it equal or exceed it. We have already discussed, in Part II B supra, the special problem of collusion between offender and enforcer that comes about because the offender, if he can turn himself in for the reward, may thereby escape the costs of punishment for his unlawful activity. 
55. This need not be true if the defendant has limited resources to finance his defense (see Richard A. Posner, supra note 51 , at 417), but such an assumption seems out of place in the present discussion, where complete reliance on a system on monetary penalties is assumed. In any event, the problem can be eliminated, though not costlessly, by the provision of counsel at the expense of the state to the indigent accused.

56. The present rule against entrapment applies only to public enforcement, but if criminal enforcement were privatized the rule could readily be extended to cover private enforcers. Again, the question arises why, under an optimum system of penalties, solicitations or inducements to commit crimes should be treated differently from ordinary selling efforts. The answer may be that entrapment normally involves misrepresentation--the individual who is encouraged to commit the crime does not know that he will not be permitted to retain its fruits.

57. Victim rights appear not to be feasible in the case of uncompleted crimes--the victim will often be unaware that the attempt to commit a crime against him has been made. This implies that the private prosecution of attempts would remain an area where rights to legal claims were acquired on a first-come first-served basis, even if the general rule was that such rights were owned by the victims of crime. 
58. However, the empirical findings of a study in which public prosecutors were assumed to seek merely to maximize weighted convictions suggest that this assumption has considerable explanatory power. See William M. Landes, An Economic Analysis of the Courts, 14 J. Law \& Econ. 61 (1971).

59. Probably a small fraction. See Richard A. Posner, supra note 51 , at $410-15$.

60. When legal error is introduced, the $p$ and $f$ derived from minimizing the social loss function (with or without constraints) would differ from their corresponding values in an errorless system, but we ignore these differences in our analysis.

61. As $p$ falls, the number of offenses rises. Hence if $\varepsilon_{p}$ were greater than unity, 0 would rise proportionately more than $p$ would fall and the number of convictions of both innocent and guilty persons would rise. However, we have assumed throughout that $\varepsilon_{p}$ is less than unity (see note 35 supra).

62. This analysis obviously has implications, not explored in this article, for the appropriate role of the state in areas besides law enforcement. It does not, however, impair the traditional argument for public provision of national defense, a type of law enforcement. Fines paid to enforcers are not practicable in that context because there is no institution to compel an aggressor to pay the victims of aggression a fine. 
63. See Richard A Posner, The Social Costs of Monopoly and Regulation (Nat'1 Bur. Econ. Res., Working Paper No. 55, Sept. 1974). The costs of monopolizing could be reduced, even under the franchise approach, if an auction system were substituted for the usual methods of granting public franchises.

64. This is not universally true. In England and Western Europe, the victim of a crime is frequently permitted to prosecute if the public prosecutor declines to do so. See Bernard M. Dickens, Control of Prosecutions in the United Kingdom, 22 Int'1 \& Comp. L. Q. 1 (1973); John H. Langbein, Controlling Prosecutional Discretion in Germany, 41 U. Chi. L. Rev. 439 (1974); Joachim Hermann, The Rule of Complusory Prosecution and the Scope of Prosecutional Discretion in Germany, id. at 468 . In several states in this country, private prosecution of crimes is permitted if the public prosecutor consents. See Note, Private Prosecution--The Entrenched Anomaly, 50 N.C.L. Rev. 1171 (1972). The practical significance of these islands of private prosecution may be small, however. Since most criminals are judgment-proof, the incentive of private individuals to prosecute for crime would ordinarily require that a bounty be offered for successful prosecution, and it is not. In the absence of a bounty or a solvent defendant, private enforcement encounters serious free-rider problems. However, some criminal actions are still brought privately in England, for example by department stores against shoplifters, where the benefits to the individual store of establishing a reputation for vigorous enforcement are presumably great. 
65. Sometimes the parties to contracts opt out of the public court system by agreeing to arbitrate any issue arising under the contract. Even there, the state is in the background: the party to an arbitration proceeding can obtain a court order compelling compliance with the award of the arbitrator.

66. Partly, to be sure, as a result of criminal and other regulatory statutes involving licensing of drivers, registration of vehicles, and punishment for leaving the scene of an accident.

67. See Gary S. Becker, supra note 11, at 192, for a proof of this result.

68. Although a bribe per se is a transfer payment rather than a cost, the opportunity to obtain bribes will attract resources into efforts to obtain the opportunity until, at the margin, cost and gain are equated.

69. Bribery of enforcers, if the bounty is set below the cost of punishment to prevent overenforcement; collusion between enforcers and offenders if it is set above cost.

70. A possible counterexample should be noted here. Price fixing is a concealable activity, and consistently with our analysis is punished as a crime. But private prosecution, in the form of treble-damage suits by the victims of price fixing, is also permitted, and it is 
70 continued

widely assumed that the threat of these actions is the most effective deterrent to price fixing; the reason seems to be that the maximum criminal penalty for price fixing (one year in prison and a $\$ 50,000$ fine) is far below both the optimal level and the penalty meted out in private actions (thrice the overcharge), which is also, in all probability, suboptimal. If $f$ in both public and private actions were, say 100 times the overcharge, the appropriateness of allowing private actions would have to be reexamined.

71. See generally Kenneth W. Dam, Class Actions: Efficiency, Compensation, Deterrence, and Conflict of Interest, 4 J. Leg. Studies (1975).

72. We have in mind the provision in the tetracycline class-action settlement whereby proceeds unclaimed by the victims of the conspiracy were allowed to escheat to the states in which those victims resided. See State of West Virginia v. Chas. Pfizer \& Co., 440 F.2d 1079 (2d Cir. 1971).

73. Cf. Arnold Plant, The Economic Theory concerning Patents for Invention, 1 Economica (n.s.) 30 (1934).

74. The requirements of novelty, utility, and nonobviousness, administered by the Patent office, and by the courts in patent-infringement actions, are the means by which the patent laws deal with the second problem 
74 continued

discussed above. The first is dealt with by, for example, the rule that disclosure of an invention is protected if the inventor files for a patent within a year following disclosure. For an analogy from the history of private enforcement in England see 2 Leon Radzinowicz, supra note 4 , at 138-39, n.2.

75. Commonly today after a class action is filed other lawyers attempt to jump on the bandwagon by appearing as representatives of other members of the class, subclasses, related classes, etc. When it comes time to award attorneys' fees the judge has to evaluate the various attorneys' contributions. The presence of multiple attorneys is not entirely a bad thing since the competition among them may reduce the problem of the class attorney who "sells out" the class by agreeing with the defendant on a settlement that involves a small award of damages and a large award of attorney's fees.

76. This assumes that once $C$ had sued and collected from $A, B$ could not also obtain damages from $A$ and thereby subject $A$ to double liability.

77. There would be, to be sure, a "moral hazard" problem if claims were freely transferable. After the victim had sold his claim to the enforcer, the latter might have difficulty enlisting the victim's cooperation in testifying against the defendant, etc. This would not appear, however, to be a more serious problem than similar problems often encountered in contractual situations when payment precedes performance. 
77 continued

Free transferability of claims might be an efficient alternative to the class action, but this would depend on the transaction costs of using the market to aggregate a large number of very small claims.

78. Cf. the statistics on agency budgets in George J. Stigler, The Process of Economic Regulation, 17 Antitrust Bul1. 207 (1972); Richard A. Posner, The Behavior of Administrative Agencies, $1 \mathrm{~J}$. Leg. Studies $305,320(1972)$.

79. In fiscal year 1973, the IRS audited fewer than two per cent of the total federal tax returns filed, and found additional tax due, amounting in the aggregate to more than $\$ 4$ billion, in more than two-thirds of the returns audited. 1973 Internal Revenue Service Ann. Rep. v, 25, 33. The total cost of its audits, however, was less than $\$ 450$ million (id. at 145), which means that, on average, one dollar spent on auditing yielded nine dollars in additional tax revenues. It is possible that although average revenue for the Service was nine times average cost, marginal revenue and marginal cost were equal. However, given the small percentage of returns audited, the high percentage of those audited that result in the assessment of additional tax due, and the extremely low ratio of cost to revenue for those returns that are audited, it seem highly unlikely that no further expansion of audit activity could be cost justified. 
28.

80. This would, however, give enforcers an incentive to bribe taxpayers to violate the law. See note 54 supra.

81. See., e.g., Abraham D. Sofaer, The Change-of-Status Adjudication: A Case Study of the Informal Agency Process, $1 \mathrm{~J}$. Leg. Studies 349 (1972).

82. This observation is not limited to public rules. "Working to rule" is a familiar method by which employees disrupt their employers' operations in order to obtain higher wages or better working conditions without striking.

83. This analysis is developed in Isaac Ehrlich \& Richard A. Posner, The Economics of Legal Rulemaking, $3 \mathrm{~J}$. Leg. Studies 257 (1974).

84. Cf. Richard A. Posner, supra note 78 , at 305-23.

85. Becker and Stigler suggest that the efforts of private enforcers to enforce the laws as they are written would lead to irresistible pressure to redraft the laws so as to eliminate those prohibitions that are not enforced by public agencies today because the forbidden conduct is innocuous or beneficial (supra note 2, at 15). But this might happen only because the cost of reformulating the law to eliminate overinclusion was less than the cost of enforcing the law in its existing form to the hilt, and the lesser of these two costs might still be greater than the cost of discretionary nonenforcement, 
85 continued

especially since the costs of legislative enactment are probably quite high. See Isaac Ehrlich \& Richard A. Posner, supra note 83, at 267-68. Incidentally, the low repute in which informers have long been held appears to be related to their role in the enforcement of unpopular laws which a politically responsive enforcer might ignore. See 2 Leon Radzinowicz, supra note 4 , at 147-48.

86. See Alan W. Scheflin, Jury Nullification: The Right to Say No, 45 So. Calif. L. Rev. 162 (1972).

87. See Kenneth W. Dam, Fortner Enterprises v. United States: "Neither a Borrower, Nor a Lender Be", 1969 Sup. Ct. Rev. 1 (Philip B. Kurland ed.).

88. A notable though rather neglected precedent is International Business Machines Corp. v. United States, 343 F.2d 914 (Ct. C1. 1965).

89. See, e.g., Kenneth Culp Davis, Discretionary Justice--A Prel iminary Inquiry (1969), and An Approach to Legal Control of the Police, 52 Tex. L. Rev. 703, 714 (1974).

90. It would interfere with the executive function of establishing and implementing enforcement priorities designed to maximize the agency's effectiveness within its budget constraint. 
91. Actually less, for reasons stated earlier (at $p$. ) but immaterial to the present analysis.

92. Overenforcement would still result if the blackmail price exceeded the fine that would induce the same $p$ with private enforcement as would be obtained with public enforcement at $f^{*}$ in Figure 5 .

93. Of course, rewards are also offered for lost property, and our analysis is applicable to those cases although they are not examples of law enforcement as it is usually defined.

94. The impact is unclear. Rewards may induce an increase in offenses since the reward provides a ready market. Witness, for example, the return of stolen art to insurance companies and ultimately the owner. Ransom in kidnapping provides another example. On the other hand, the prospects of rewards to persons other than the thief may reduce the gains from and hence deter theft.

95. $k$ may also incorporate factors such as the nonpecuniary benefits of honesty. Presumably, the greater the degree of honesty, the lower k.

96. The second-order condition for a maximum is that $\mathrm{p}^{\prime \prime}\left(=\partial^{2} \mathrm{p} / \partial \mathrm{B}^{2}\right)<0$.

97. The social function of rewards is to transfer goods from lower-valued (the thief or finder) to higher valued uses (the original owner). An 
97 continued

interesting and difficult question is whether rewards provide a net social benefit. In the case of a casual finder of lost goods, rewards would appear to enhance values. The costs of finding the good to the casual finder are approximately zero, and hence the net expected gain to both parties is positive, as in

$$
Z=p[(V-B)+(B-k V)]>0 \text {. }
$$

On the other hand, if the finder is an enforcer who spends real resources in the process, there is no presumption that rewards will produce a social benefit, since now

$$
z-c \geqslant 0
$$

where $C$ is the enforcer'scosts. Observe that if the enforcer's victims

cost equal pB, the maximum / would be willing to spend, then

(ii) becomes

$$
\mathrm{p}[\mathrm{V}(1-\mathrm{k})-\mathrm{B}] \lessgtr 0
$$

which is more likely to be positive the smaller $k$. The problem is more difficult when we deal with theft because whether rewards increase value depends critically on the response of thieves to the prospects of rewards. For example, even if $k$ were zero--the case of kidnapping--the elimination of rewards might reduce the value of these offenses to zero.

98. See, e.g., Reynolds v. Eagle Pencil Co., 285 N.Y. 448, 35 N.E.2d 35 (1941); Fitch v. Snedaker, 38 N.Y. 248 (1868); G. C. Cheshire \& C.H.S. Fifoot, The Law of Contract 45-46 (7th ed. 1969). A minority 
32.

98 continued

of courts hold the contrary view. See, e.g., Sullivan v. Phillips, 178 Ind. 164, 98 N.E. 868 (1912).

99. An offeror of a reward has no incentive to take account of the increase in incentives of casual enforcers because, by assumption, the casual enforcer is unaware of whether a particular owner has offered a reward. Hence, the effect of expanding the legal rights to rewards would be to reduce the owner's estimate of $\varepsilon$. 